\title{
Crashworthiness Models for Automotive Batteries
}

A Report on the Department of Energy Project 2088-A031-15 for the National Highway Traffic Safety Administration (NHTSA), an Office of the U.S. Department of Transportation.

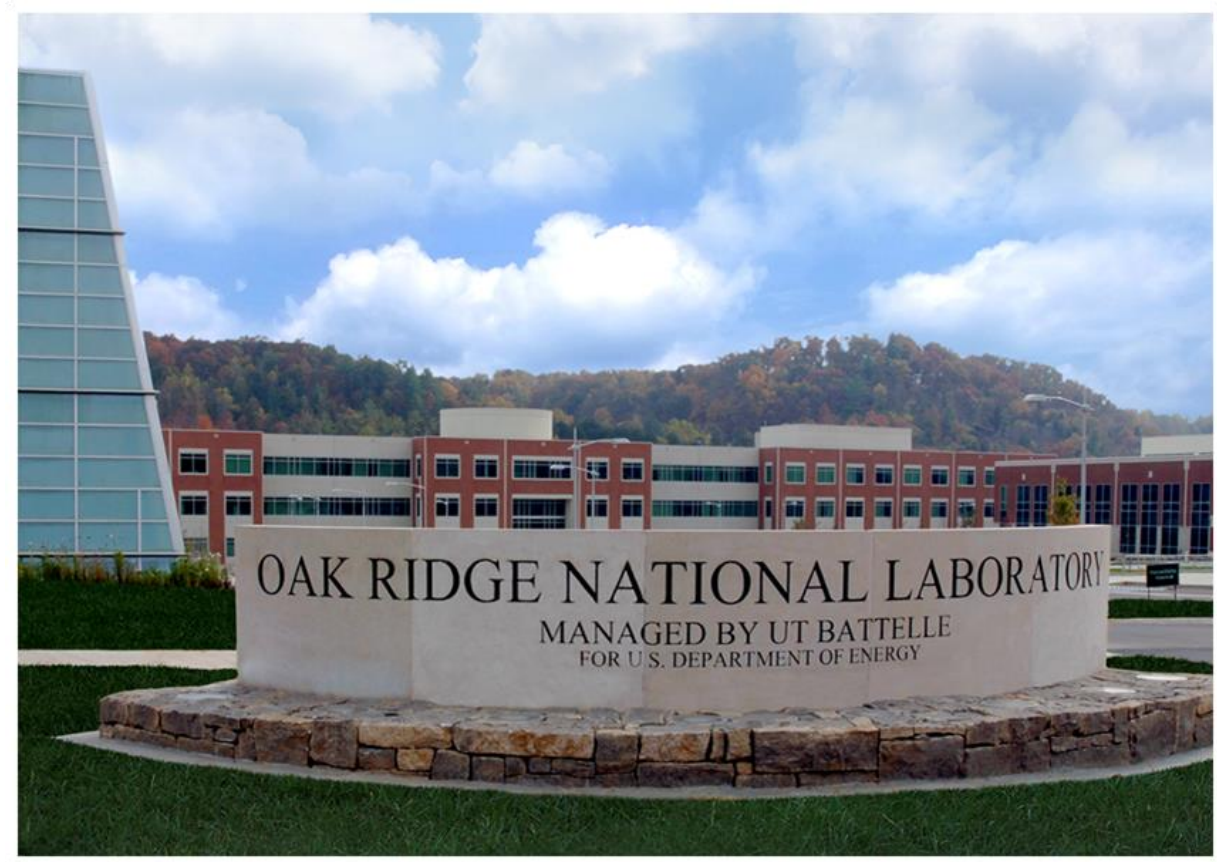

John A. Turner (PI)

Srikanth Allu

Sarma Gorti

Sergiy Kalnaus

Abhishek Kumar

Damien Lebrun-Grandie

Srdjan Simunovic

Stuart Slattery

Bruno Turcksin

Hsin Wang

July 2016 


\title{
DOCUMENT AVAILABILITY
}

Reports produced after January 1, 1996, are generally available free via US Department of Energy (DOE) SciTech Connect.

Website http://www.osti.gov/scitech/

Reports produced before January 1, 1996, may be purchased by members of the public from the following source:

\author{
National Technical Information Service \\ 5285 Port Royal Road \\ Springfield, VA 22161 \\ Telephone 703-605-6000 (1-800-553-6847) \\ TDD 703-487-4639 \\ Fax 703-605-6900 \\ E-mail info@ntis.gov \\ Website http://www.ntis.gov/help/ordermethods.aspx
}

Reports are available to DOE employees, DOE contractors, Energy Technology Data Exchange representatives, and International Nuclear Information System representatives from the following source:

Office of Scientific and Technical Information

PO Box 62

Oak Ridge, TN 37831

Telephone 865-576-8401

Fax 865-576-5728

E-mail reports@osti.gov

Website http://www.osti.gov/contact.html

\begin{abstract}
This report was prepared as an account of work sponsored by an agency of the United States Government. Neither the United States Government nor any agency thereof, nor any of their employees, makes any warranty, express or implied, or assumes any legal liability or responsibility for the accuracy, completeness, or usefulness of any information, apparatus, product, or process disclosed, or represents that its use would not infringe privately owned rights. Reference herein to any specific commercial product, process, or service by trade name, trademark, manufacturer, or otherwise, does not necessarily constitute or imply its endorsement, recommendation, or favoring by the United States Government or any agency thereof. The views and opinions of authors expressed herein do not necessarily state or reflect those of the United States Government or any agency thereof.
\end{abstract}


Computer Science and Mathematics Division (CSMD)

Materials Science and Technology Division (MSTD)

\title{
Crashworthiness Models for Automotive Batteries
}

A Report on the Department of Energy Project 2088-A031-15

for the

National Highway Traffic Safety Administration (NHTSA)

an Office of the

U.S. Department of Transportation (DOT)

\author{
John A. Turner (PI) \\ Srikanth Allu \\ Sarma Gorti \\ Sergiy Kalnaus \\ Abhishek Kumar \\ Damien Lebrun-Grandie \\ Srdjan Simunovic \\ Stuart Slattery \\ Bruno Turcksin \\ Hsin Wang
}

Date Published:

July 2016 


\section{Prepared by \\ OAK RIDGE NATIONAL LABORATORY \\ Oak Ridge, TN 37831-6283 \\ managed by \\ UT-BATTELLE, LLC \\ for the \\ US DEPARTMENT OF ENERGY \\ under contract DE-AC05-00OR22725}




\title{
Crashworthiness models for automotive batteries.
}

\author{
Report on the Department of Energy Project 2088-A031-15 for the National \\ Highway Traffic Safety Administration (NHTSA), an Office of the U.S. \\ Department of Transportation.
}

John A. Turner (PI), Srikanth Allu, Sarma Gorti, Sergiy Kalnaus, Abhishek Kumar, Damien Lebrun-Grandie, Srdjan Simunovic, Stuart Slattery, Bruno Turcksin, Hsin Wang.

\section{Summary}

Safety is a key element of any device designed to store energy, in particular electrochemical batteries, which convert energy of chemical reactions to electrical energy. Safety considerations are especially important when applied to large automotive batteries designed for propulsion of electric vehicles (EV). The high amount of energy stored in EV battery packs translates to higher probability of fire in case of severe deformation of battery compartment due to automotive crash or impact caused by road debris. While such demand for safety has resulted in heavier protection of battery enclosure, the mechanisms leading to internal short circuit due to deformation of the battery are not well understood even on the level of a single electrochemical cell. Moreover, not all internal shorts result in thermal runaway, and thus a criterion for catastrophic failure needs to be developed.

This report summarizes the effort to pinpoint the critical deformation necessary to trigger a short via experimental study on large format automotive Li-ion cells in a rigid spherical indentation configuration. Cases of single cells and cell stacks undergoing indentation were investigated. Mechanical properties of cell components were determined via experimental testing and served as input for constitutive models of Finite Element (FE) analysis. The ability of the model to predict the behavior of cell(s) under spherical indentation and to predict failure leading to internal short circuit was validated against experiments. The necessity of resolving pairs of negative and positive electrodes in the FE formulation is clearly demonstrated by comparing layer-resolved simulations with simulations involving batteries with homogenized material properties. Finally, a coupled solution of electrochemical-electrical-thermal (EET) problem on a Nissan Leaf battery module was demonstrated towards the goal of extending the simulations to module level. 


\section{Contents}

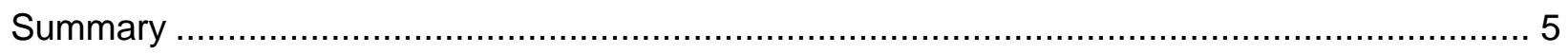

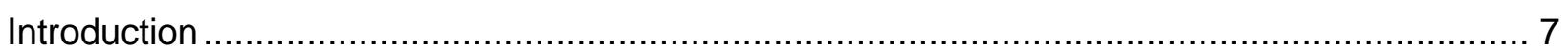

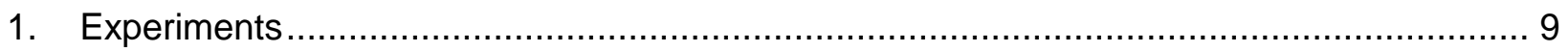

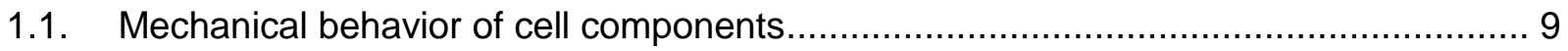

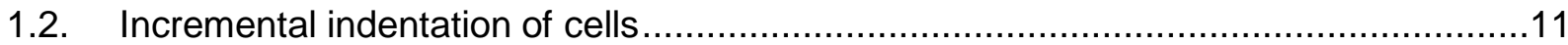

1.2.1. Indentation of single cells and cell stacks........................................................

1.2.2. Results of indentation of cells and cell stacks ............................................14

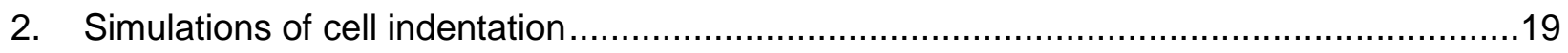

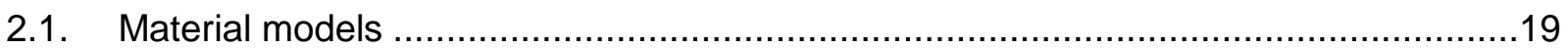

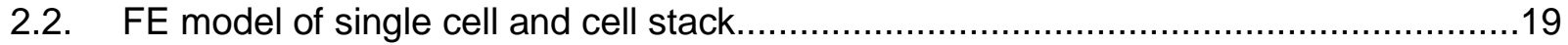

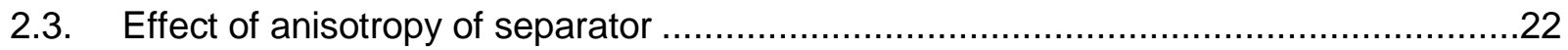

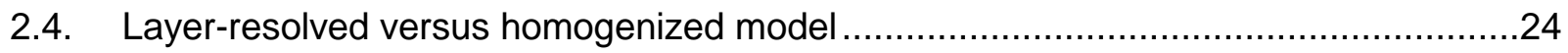

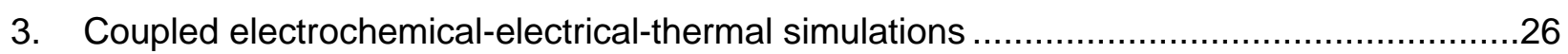

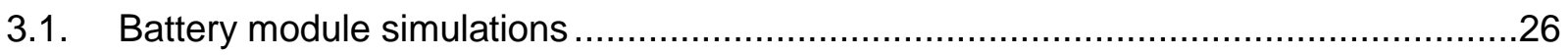

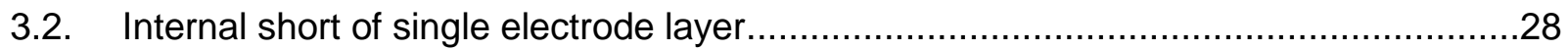

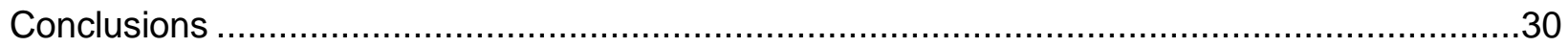

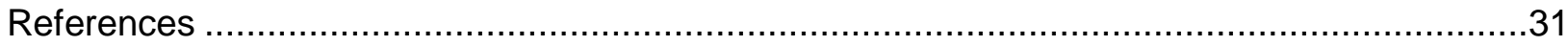

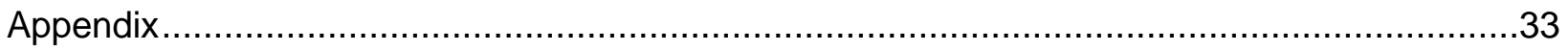




\section{Introduction}

Li-ion batteries for mobile electronic devices and appliances are usually in the form of single cells or small cell packs, where mechanical abuse could occur by handling of the cells during transportation and storage. The end-users are not subjected to risks from mechanical abuse under normal conditions. Although the once in several million chance of self-induced internal short circuit event has always been a potential safety concern, recent advances in cell chemistry, safer electrolytes, separators [1], and battery management system (BMS) have kept this issue a low priority. The emphasis on more specific power in mobile devices has led to current Li-ion cells to share the same designs with a light-weight pouch cell and thinner layers of current collectors and separators. They are vulnerable to mechanical abuses such as crushing, bending and dropping. For electric vehicle (EV) applications, the same designs for small cells were simply scaled up in dimensions to make large format cells. The larger cells carry significantly more energy and also inherit the same mechanical abuse-intolerant characteristics of their smaller counterparts. For the same mechanical damage and same state of charge (SOC), a larger cell is more likely to go to thermal runaway because it has higher capacity and more current can flow through the short circuit spot to trigger thermal runaway. With the increasing number of electrical vehicles entering the active fleet, battery safety has become an important issue [2]. In addition to the safety of handling and transporting the cells, the EV users can be directly affected by the mechanical abuses and failure of the batteries. In order to avoid mechanical damage, the cell packs are located in the crush-safe zones and protected by extra armors. However, severe accidents can still lead to mechanical deformation of the cells, short circuit in the cells and potential thermal runaway.

A damage tolerant design of batteries rests upon detailed understanding of the processes leading to failure and the ability to model such processes. Such understanding is especially critical in the case of battery pack designs for electric vehicles. Current lack of such understanding is not surprising, considering the difficulty of the problem, which combines mechanics of battery response to crush loading with electrical and chemical behavior. While there are federal safety regulations [3] and industry standards related to battery safety [4, 5], they mostly address passive safety measures such as electrolyte spillage or disconnection of the high voltage battery pack in case of malfunction.

A number of tests on safety of Li-ion cells under mechanical abuse has been developed over the years, with probably the most well-known being the "nail penetration tests" standardized by SAE as J2462 [6]. Majority of the recommendations for abuse testing of automotive batteries can be found in "Abuse Test Manual for Electric and Hybrid Electric Vehicle Applications" released by Sandia National Laboratories [7]. It should be mentioned that unavoidable manufacturing variability results in difficulties in the determination of location of short circuit and formulation of criteria for thermal runaway. In addition, most of the tests are destructive, and post-mortem analysis cannot supply definitive evidence regarding the origin of the short. Localized high joule heating within the internal short circuit can trigger a chain of exothermic reactions that raise the temperature enough to create combustion of flammable gases in the cell (thermal runaway).

This report summarizes progress in development of an indentation test, executed on a single pouch cell, or a string of cells, and subsequent FE analysis. The experiment is designed to pinpoint the onset of short circuit through incremental indentation with subsequent disassembly and analysis of the cells. Thus a very clear goal is determination of the critical deformation leading to the cell failure under spherical indentation. The common assumption is that in this loading mode, the internal short occurs due to thinning of the separator under the spherical indenter. With data from incremental indentation available, a Finite Element modeling of cell mechanics was used to model the response of the cell and cell string under external loading. Mechanical properties of the cell components, i.e. pouch material, positive and negative 
electrodes, and polymer separator, were measured to provide input for mechanics models. In order to capture the behavior of the cell and track the strains in the separator, each cell component in the top 4 layers was resolved in the FE model. In addition, anisotropic behavior of the separator in tension was taken into account. Resolving four layers was deemed sufficient based on the analysis with increasing number of resolved electrode layers up to the full 17 cell sandwiches representing the complete pouch cell. Such resolution, and formulation of failure based on strain in the separator, clearly distinguishes the current approach from other studies reported in literature where the cells undergoing impact are modeled using homogenized material, with failure criterion chosen to match the experimental data. Such failure criterion for homogenized material needs to be re-calibrated for any change in cell geometry or diameter of the indenter and thus the approach lacks in predictive capability. The current report clearly demonstrates the above result by comparing layer-resolved and homogenized battery models under identical indentation conditions.

Finally we report on coupled electrochemical, electrical, and thermal simulations of a 4-cell battery module. The module corresponds to that of a Nissan Leaf and the FE mesh was applied to a CAD model which included all the components in the module. 


\section{Experiments}

\subsection{Mechanical behavior of cell components}

The response of positive and negative electrodes in compression was determined using an Instron servo-hydraulic machine. The electrodes were pre-cut into $17 \times 17 \mathrm{~mm}$ square pieces that were stacked together and compressed between two flat plates. The positive electrode was based on $\mathrm{Li}\left[\mathrm{Ni}_{1 / 3} \mathrm{Mn}_{1 / 3} \mathrm{Co}_{1 / 3}\right] \mathrm{O}_{2}$ and the negative electrode was Conoco Philips A12 graphite. The number of layers in the stack ranged from 19 to 28 , with the average stack thickness of $3 \mathrm{~mm}$. A total of 19 experiments were conducted.

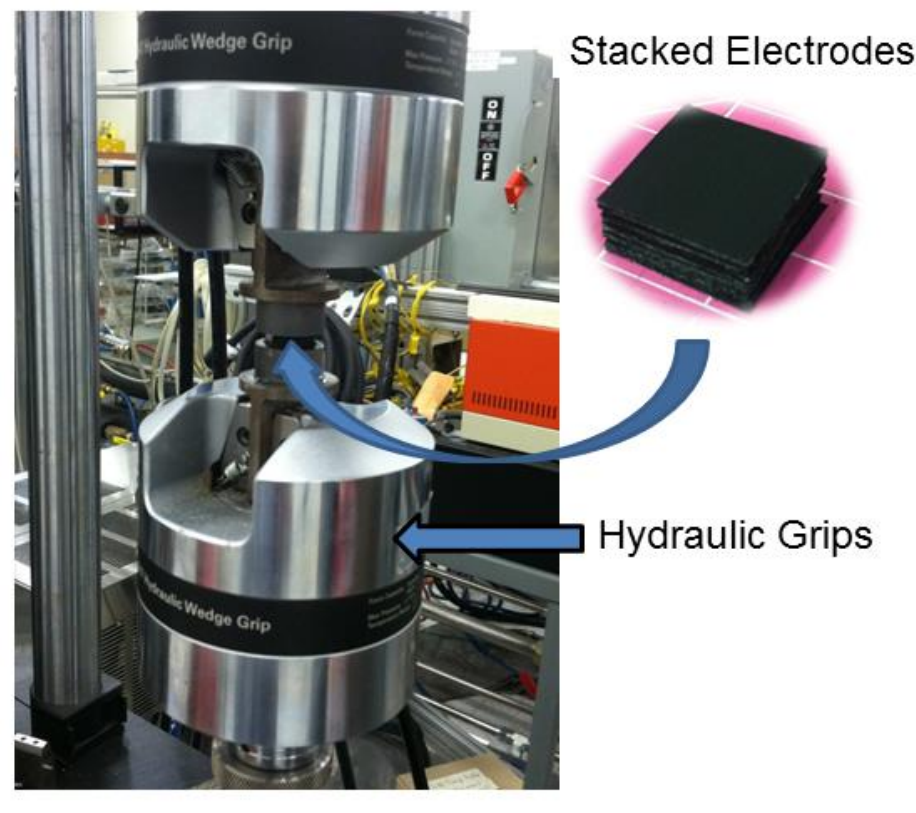

(a)

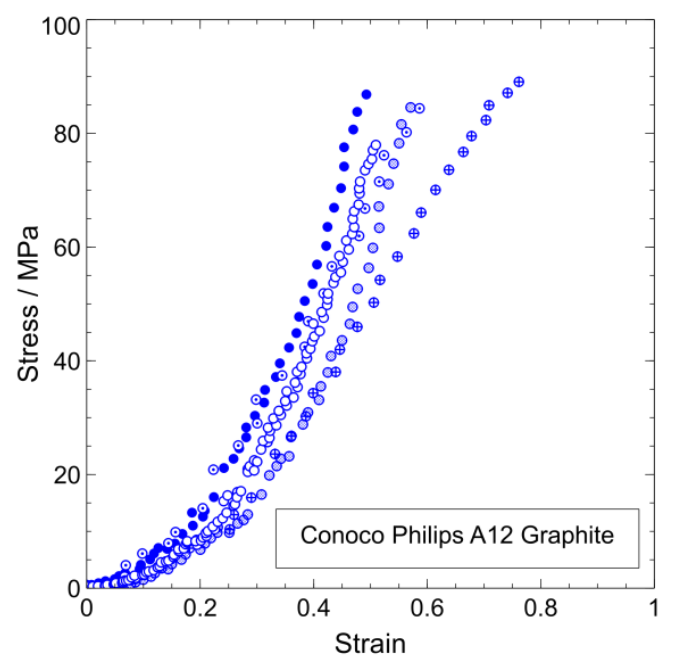

(c)

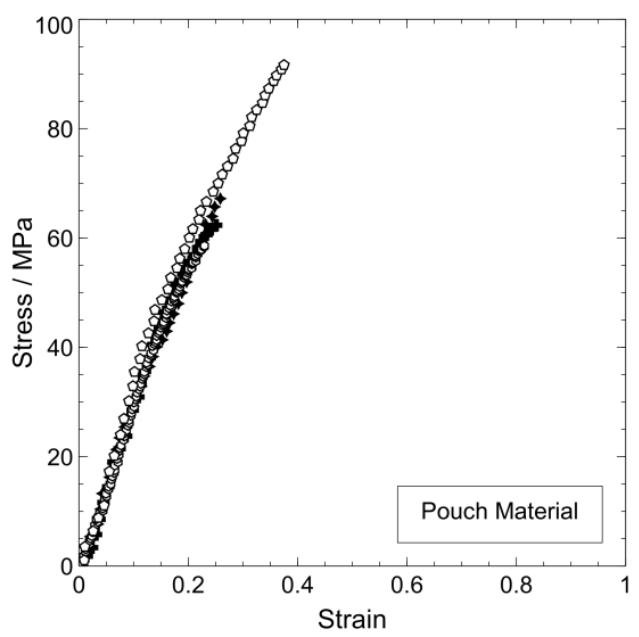

(b)

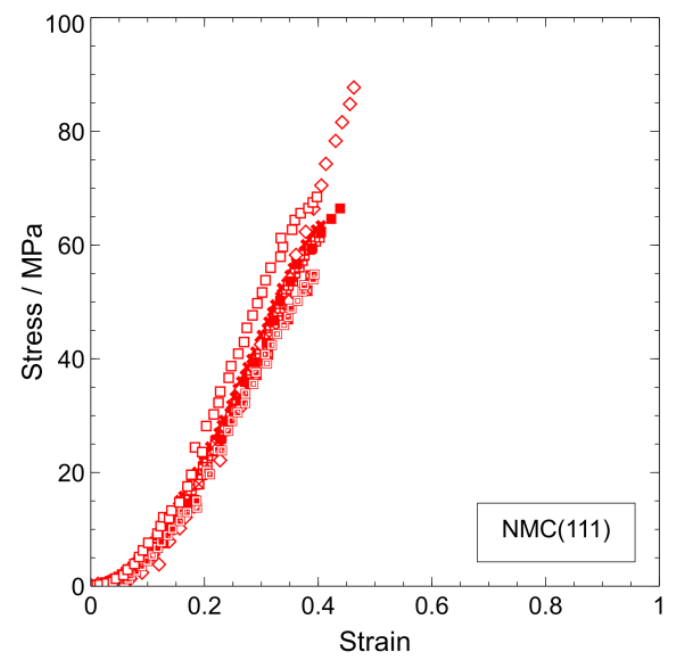

(d)

Fig. 1. Compression mechanical testing of battery components. (a) setup; (b) pouch material; (c) negative electrode; (d) positive electrode. 
Celgard 2325 separator was tested in tension in dry condition. Experiments were done under displacement control in MTS load frame with 50 lbs $(\sim 0.2 \mathrm{kN})$ load cell. Digital image correlation (DIC) was used to measure the strain. Wedge grips were used to hold the sample; rubber inserts were placed inside the grips to prevent tearing of separator (Fig. 2). Samples were approximately $6 \mathrm{~cm}$ long strips with width ranging from $2 \mathrm{~cm}$ to $1 \mathrm{~cm}$. The gage length was kept close to $30 \mathrm{~mm}$.

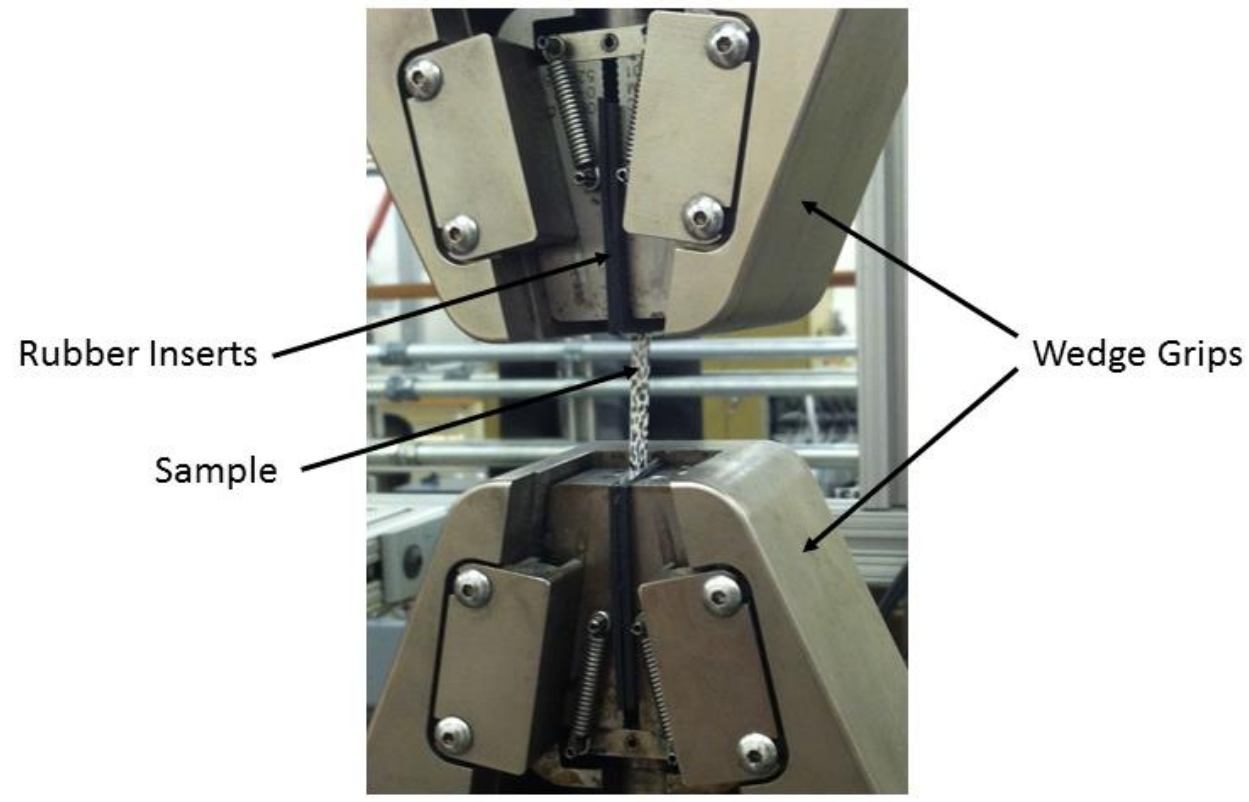

Fig. 2. Setup for separator tensile test.

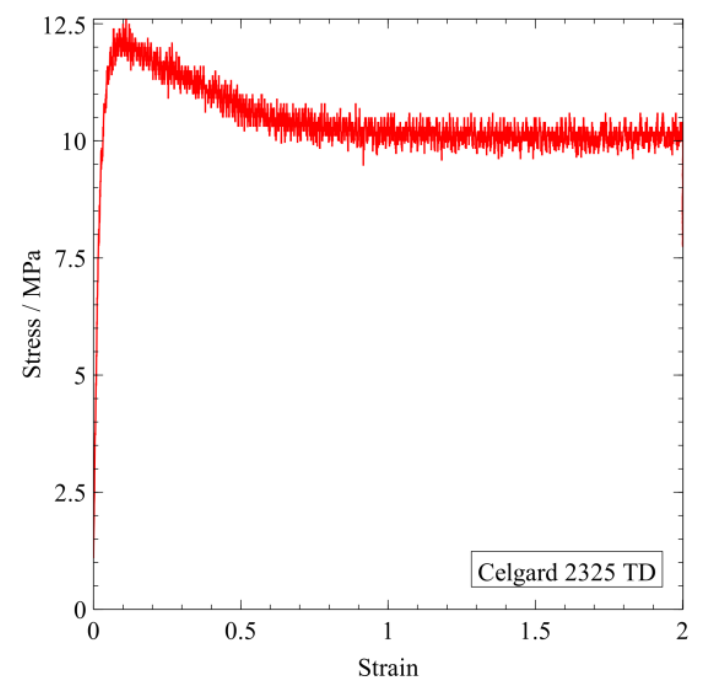

(a)

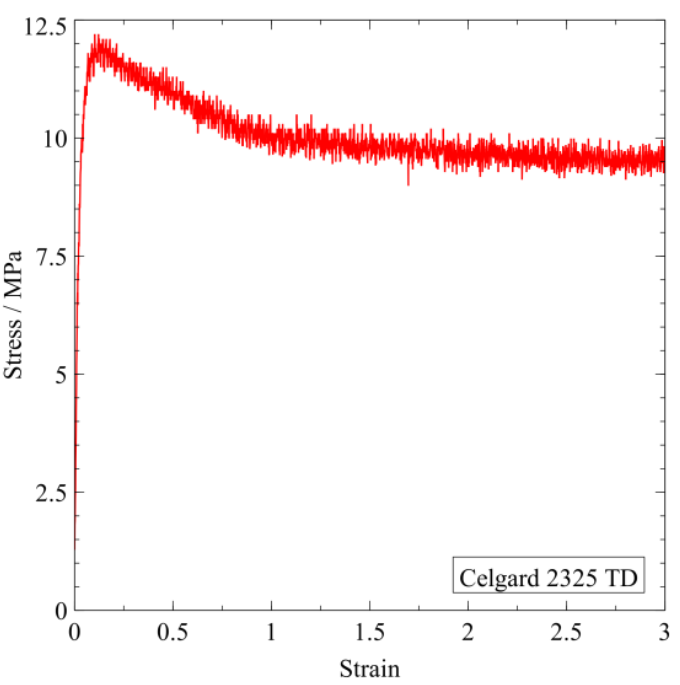

(b) 


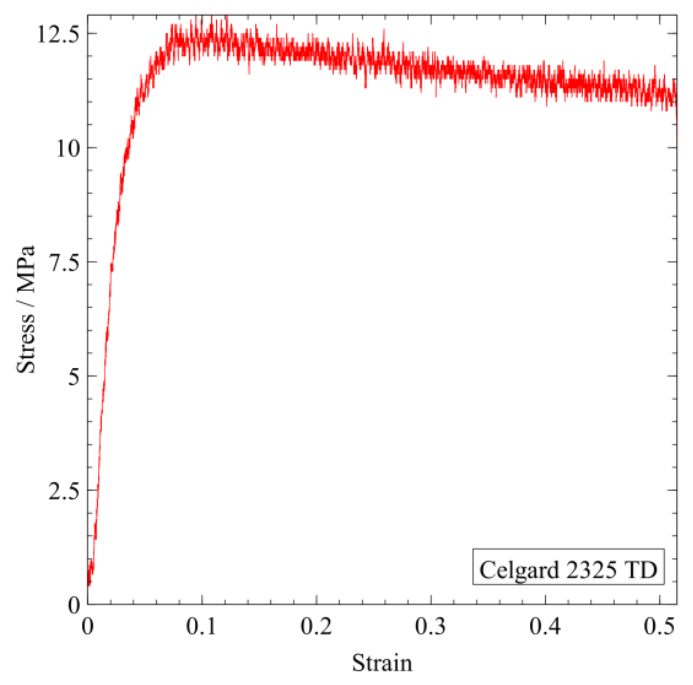

(c)

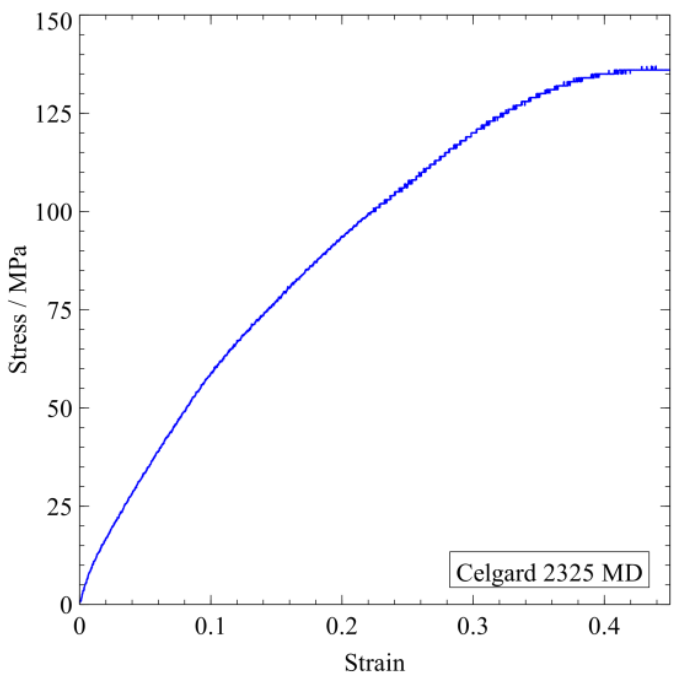

(d)

Fig. 3. Tensile stress-strain curves of Celgard 2325 separator. (a-c) transverse direction; (d) machine direction.

The tensile stress-strain curves of Celgard 2325 separator are shown in Fig. 3. Significant difference in strength can be observed between machine and transverse directions (MD and TD correspondingly). As a first approximation, a factor-of-10 rule can be used to compare the stresses in the two directions. Very high strains were developed in TD samples, up to $300 \%$. The tests in TD were not terminated with specimen rupture, rather either the boundaries of field of view of the DIC camera were exceeded as the specimen was pulled or the displacement limit of the crosshead was reached which stopped the test. Considerable softening can be observed in TD oriented samples.

\subsection{Incremental indentation of cells}

Various studies can be found in the literature on mechanical testing of Li-ion cells [8]. For small cells used in mobile devices, UL 1642 [9] describes four mechanical abuse tests that the cells with less than 5 grams of metallic lithium must pass, including crushing, impact, shock and vibration. These tests mainly focus on possible mechanical abuses during the transportation and storage of the cells. The passing criteria for these tests are: no fire and no explosion. For self-induced internal short circuit there is no standard test. Most techniques were developed to simulate an internal short circuit at a single layer due to manufacturing defects. Alternative ways to simulate such a defect require opening a live cell and putting a foreign object inside the cell $[10]$ or embedding an "instigator" inside the cell $[11,12]$. These methods work well in a laboratory environment and are not practical in production and for in-service evaluations. Nail penetration [13] or single-side indentation [14] usually can cause extensive damages to the cell before the short circuit event. Efforts to develop mechanical pinching [15] and torsion [16] tests have been made to modify the simple nail penetration or mechanical indentation tests in order to induce a small short circuit spot deep inside the cell. It is important to point out that none of the above tests can perfectly mimic an actual internal short circuit event. They can be treated as cell safety evaluation methods and are more effective in comparing cell-to-cell and design differences. 
For large format cells, no formal mechanical abuse test standards or internal short circuit tests are available, although many efforts can be found in the literature [17-19]. Mechanical testing to simulate damage in a crash situation is fundamentally different from internal short circuit simulations. These tests need to cover various externally induced mechanical deformations. In most cases, the damage involves multiple layers and in some cases multiple cells. It is common to conduct mechanical deformation tests until battery failure (usually a voltage drop) is detected. The final results are multiple layer short circuit and rapid local heating. Even with the minimal capacity, the resulting mechanical damage and localized joule heating make it very difficult to pin-point the final failure mechanism. In most accidents involving EVs, the field data are very hard to obtain, and are totally destroyed in the case of vehicle fire.

We investigate the evolution of mechanical deformation of the cell materials leading to the final failure. Commercially available Li-ion pouch cells were progressively indented using a 1.0" diameter steel ball. The indentation was performed on single cells and on stack of three cells against a thick steel plate. Mechanical characterization experiments were conducted on cell components to measure properties and develop constitutive models for simulation of indentation tests.

\subsubsection{Indentation of single cells and cell stacks}

The indentation tests were performed at the battery testing facility of the Naval Surface Warfare Center (NSWC) at Carderock, MD. A displacement-controlled test rig developed at Oak Ridge National Laboratory (ORNL) was used; a pouch cell under a single side indentation is shown in Fig. 4. The system consists of a steel frame, an electric motor-driven actuator and a load cell. It can impose displacement increments with accuracy of 0.0005 inches per revolution under displacement speeds between $0.01 \mathrm{inch} / \mathrm{min}$ and $12 \mathrm{inch} / \mathrm{min}$. The indenter vertical displacement was determined by the actual number of revolutions of the step-motor. Under compressive load the target displacement and the actual displacement may differ depending on the magnitude of applied load. We used the target displacement in the plots and discussion of the results and the actual displacement of the indenter can be found from the calibration Table 2 in Appendix.

The tests were conducted on commercially available Li-ion NMC/graphite pouch cells with capacity of $25 \mathrm{Ah}$. The loading speed was 0.25 " per minute. The reference indentation position $(z=0)$ was set to the position when the sphere was in contact with the cell and the cell could not be turned by hand with light touch. The indentation was proceeded to the set depth ( $z$ negative values), until the force levels off, and returned to $z=+0.025$ " position at the same speed. The extra elevation above the reference allowed the cell to be moved to another position. The subsequent indentations were started from the +0.025 " position assuming the cell was flat and the initial $z=0$ position applied to all subsequent tests. 5:

A total of five 25 Ah cells were tested in this study and pictures of the cells are shown in Fig.

1) Figure 5(a), Cell No. 1: Eight indentations with 1.0" diameter steel ball on the single cell against the steel plate, with progressive depths between 0.025 " and 0.200 " in increments of 0.025 ". The final, $9^{\text {th }}$, indentation was carried until short circuit was detected. The test was used to determine the range for indentation and increments needed for determining the onset of short circuit.

2) Figure 5(b), Cell No. 2: Eight indentations as for the cell no. 1. The same sequence of indentations was repeated at the lower part of the cell using 2 additional cells as backing material on top of the steel plate.

3) Figure 5(c), Cell No. 3: Five indentations of the single cell with depths of $0.100 ", 0.150 "$, $0.175 " 0.200$ and $0.210 "$. 
4) Figure 5(d), Cell No. 4: Five indentation of the single cell with depths of $0.210 ", 0.220$ ", 0.230 ", 0.240 "and 0.245 ".

5) Figure 5(e), Cell No. 5: Two indentations with depths of $0.245 "$ and $0.250 "$. The final step induced internal short circuit and thermal runaway

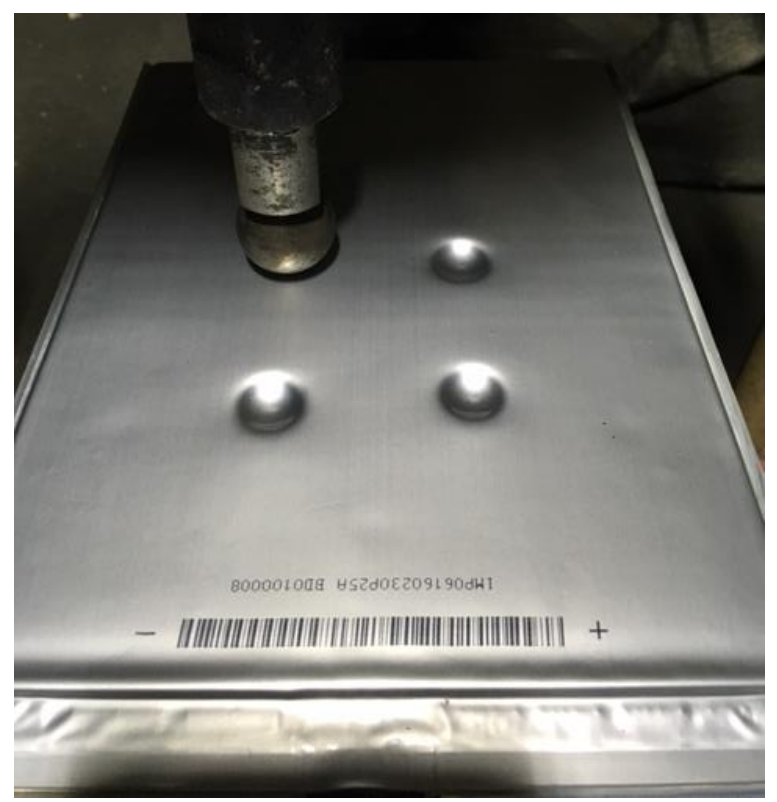

Fig. 4. Single-side indentation with a 1" diameter sphere using a load frame and motor-driven actuator at NSWC

Cell No. 1 was the initial test cell used to determine the indentation range to failure. Cell No. 2 was used to repeat the cell No. 1 test and for additional 3-cell stack indentations. Cells No. 3 and No. 4 were designed to narrow the range of short-circuit failure. Cell No. 5 was used to determine the short circuit up to the accuracy of the equipment. The first two cells were discharged to $3.00 \mathrm{~V}$ from the shipping state and recharged back to $25 \% \mathrm{SOC}$ (2.5 Ah) at $\mathrm{C} / 3$ rate. Open circuit voltage was monitored throughout the test for short circuit. The next three cells were tested with about $75 \%$ SOC.

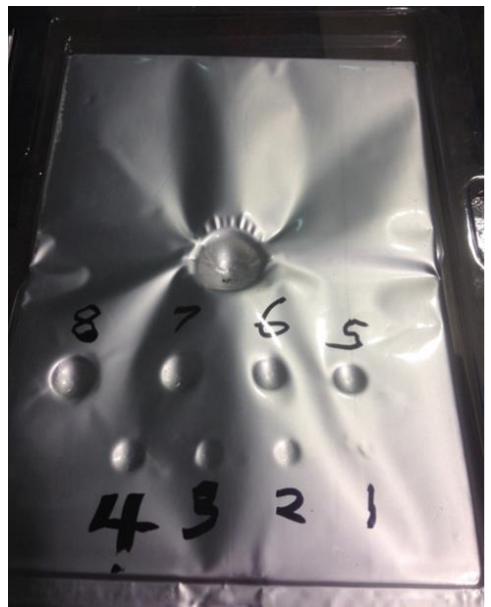

(a)

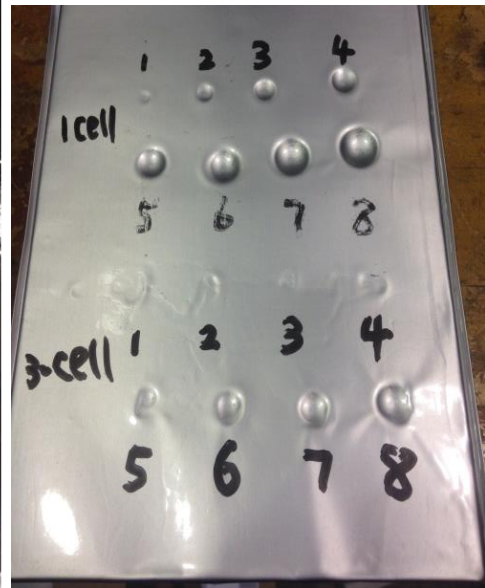

(b) 


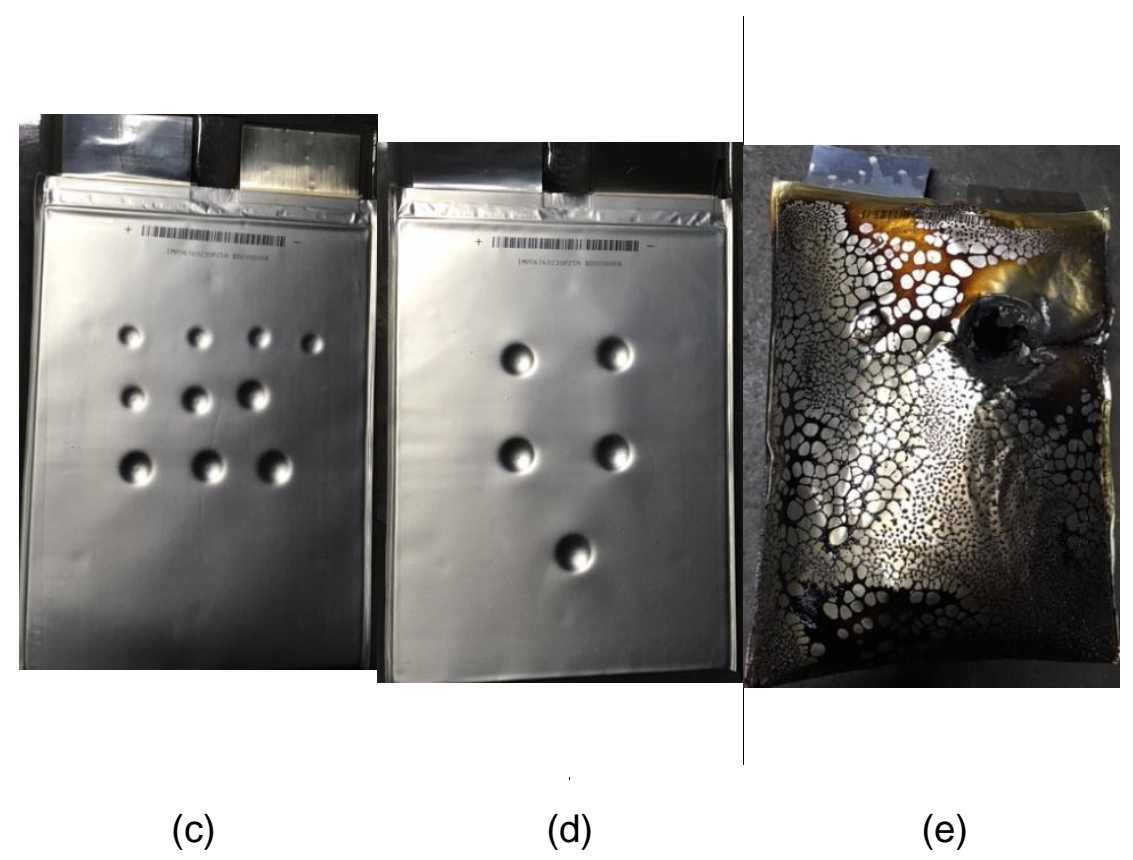

Fig. 5. (a) Cell No. 1 after 8 progressive indentations and final short circuit indentation; (b) Cell No. 2 after two set of indentations: single-cell and 3-cell, (c) Cell No.3 with 10 indentations; (d) Cell No. 4 with 5 indentations and (e) Cell No. 5 thermal runaway at 0.250 "

The short circuit in cell No. 1 was local. The 8 previous indentations away from the final step were not affected. However, materials under the indenter were fused together after the short circuit event. Cell No. 5 went to full thermal runaway with large amount of smoke release. Although Cell No. 5 was destroyed, the onset of short circuit was preserved in Cell No. 4. It was determined that using 1" diameter sphere, the 25 Ah cells could go to thermal runaway at $>0.245$ " deformation induced by compression. The tested cells were completely discharged and disassembled at ORNL for analysis of the internal configuration. Cell layers were examined for damage and indentations were photographed. The separators were digitally scanned against a black background to quantify the damage and thinning.

\subsubsection{Results of indentation of cells and cell stacks}

For a single cell indentation on a steel plate, Fig. 6 shows the results of eight indentations in Cell No. 1. The compression was stopped once the preset indentation depth was reached. The hold time depended on the load recovery time at each depth and was on the order of 10-30 seconds but not fixed. Overall, the load vs. time plots followed the same trend. The curves related to the initial 10-20 seconds are non-linear and followed by relatively linear responses all the way to the set depths. Once the compression stopped, we observed a slow recovery of the load due to the relaxation of the multiple layers. The cell was partially charged with an open circuit voltage of $3.50 \mathrm{~V}$. The voltage was monitored continuously during the indentation. No voltage drop was observed during the eight indentations.

Figure 7 shows the final indentation on cell No. 1 at the speed of 0.25 " per minute. No depth was set and the system is programmed to retract at 1 " per minute once a $0.1 \mathrm{~V}$ voltage drop is detected. The cell voltage dropped from $3.5 \mathrm{~V}$ to $0.2 \mathrm{~V}$ within a few seconds followed by heating and small amount of outgassing of the cell. With limited capacity, no thermal runaway occurred. However, localized heating and melting were observed when the cell was opened. The folding and bending of the pouch did not occur before short circuit and was mainly due to the volume expansion during outgassing as shown in Fig. 5. 
Cell No. 2 was first used to repeat the single cell vs. steel plate test as Cell No. 1. Eight indentations were made and the results are shown in Fig. 8. Other than the initial contact uncertainties in the steps 1-2, the Load vs. Time curve repeated very well with the non-linear and linear portion overlapping in each step. No short circuit was observed to the last step. The maximum load values after step \#3 were consistent with Cell \#1. Cell No. 2 was used again with two more cells as backing material on top of the same steel plate. The 3-cell stack was subjected to the same 8 indentations and the results are shown in Fig. 9. With thicker backing material, the first 4 steps had very small compressive load ( $<50$ pounds).

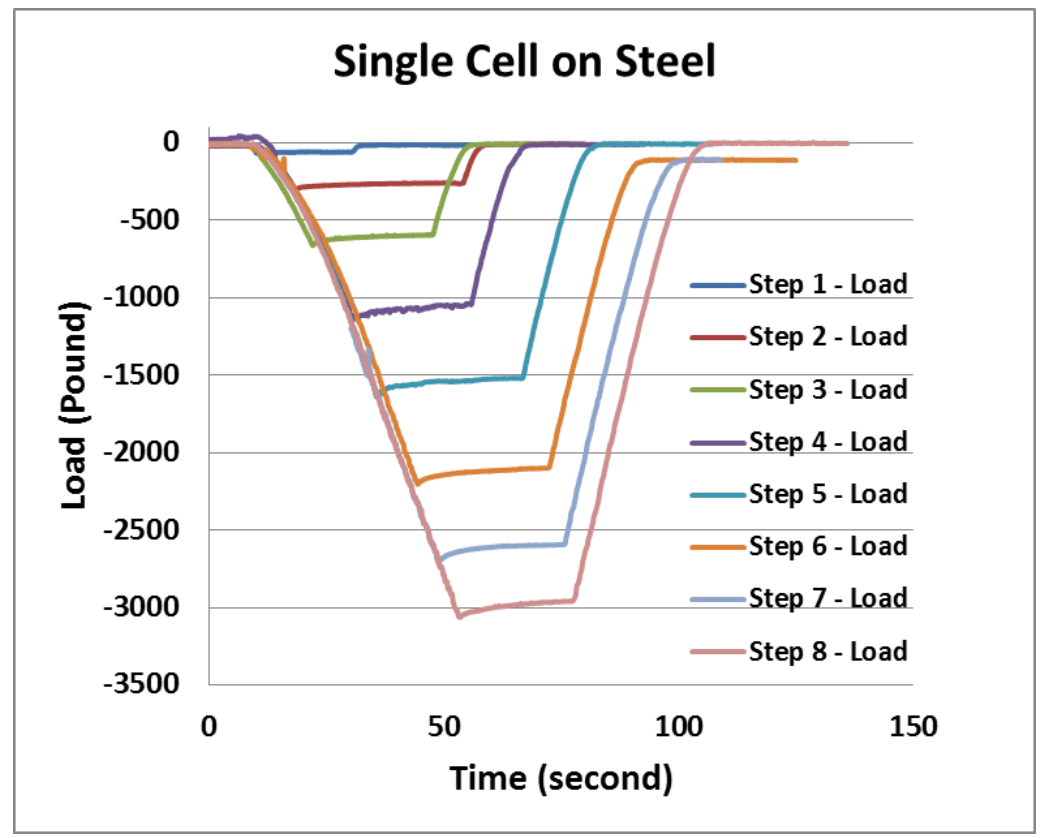

Fig. 6. Load vs. Time curves of the eight indentations for Cell No. 1 on a steel plate

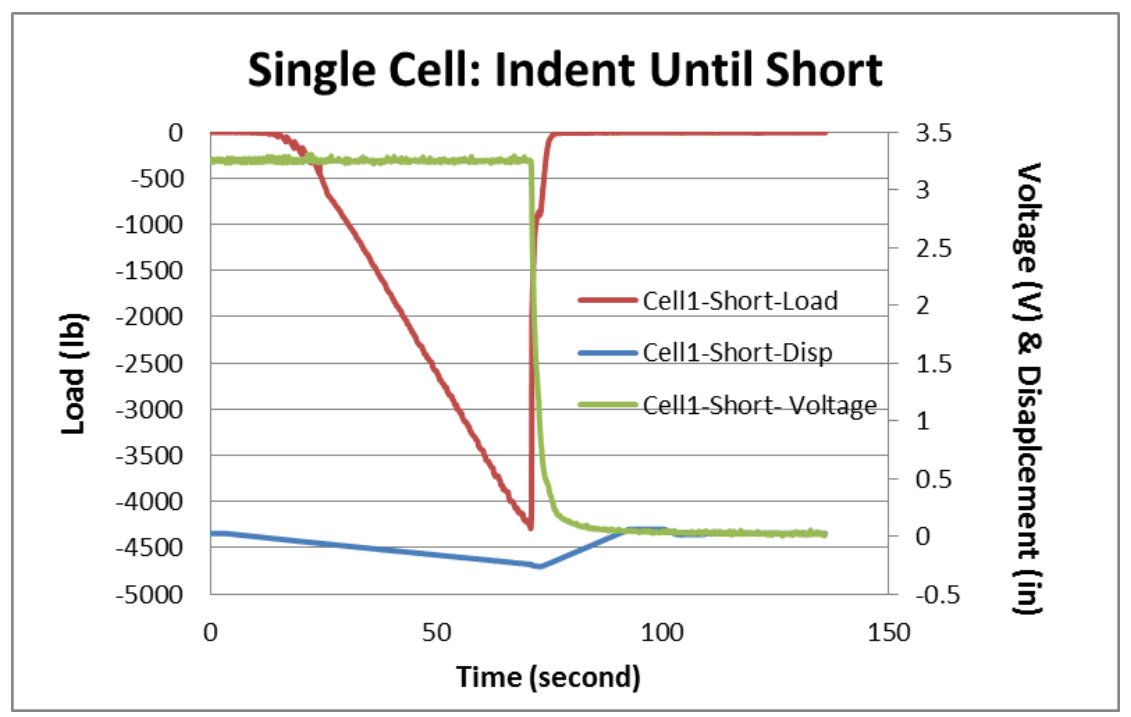

Fig. 7. Load, Voltage, Displacement vs. Time curves of the indent-to-short circuit test Cell No.1 


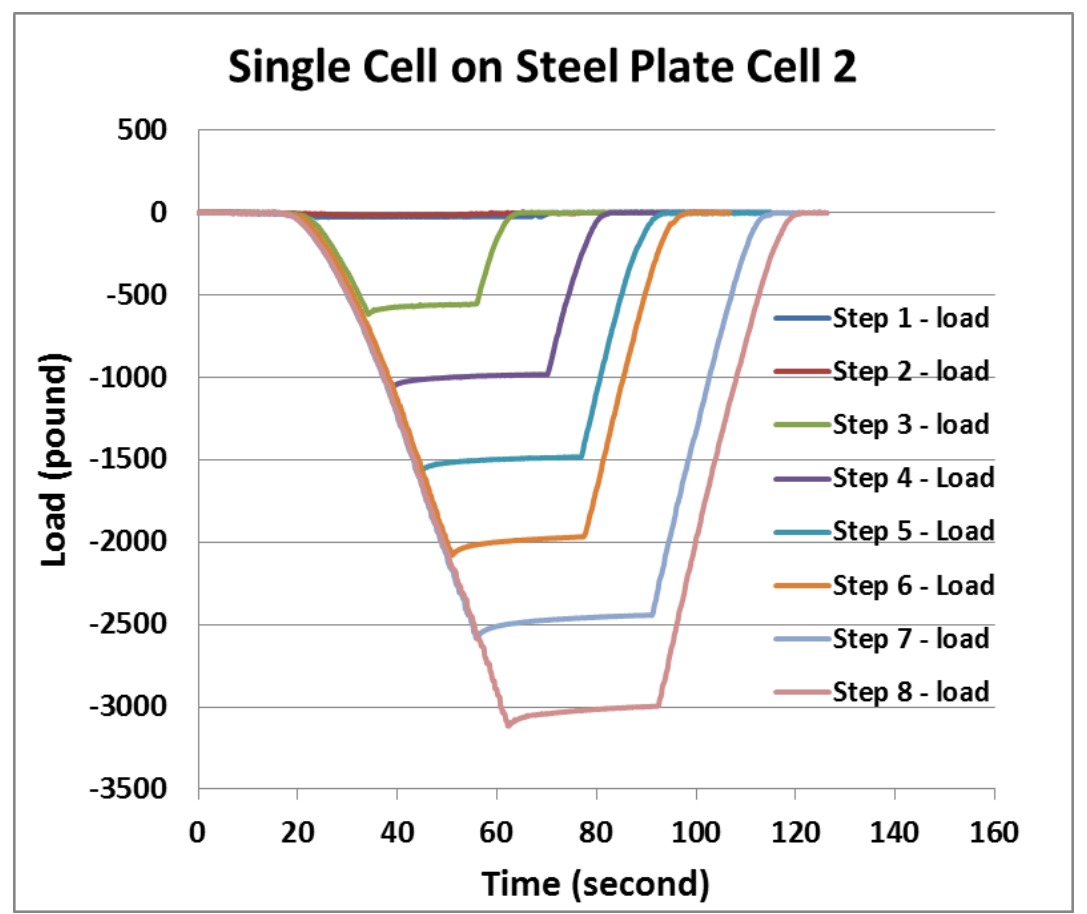

Fig. 8. Load vs. Time curves of the eight indentations for Cell No. 2 on a steel plate

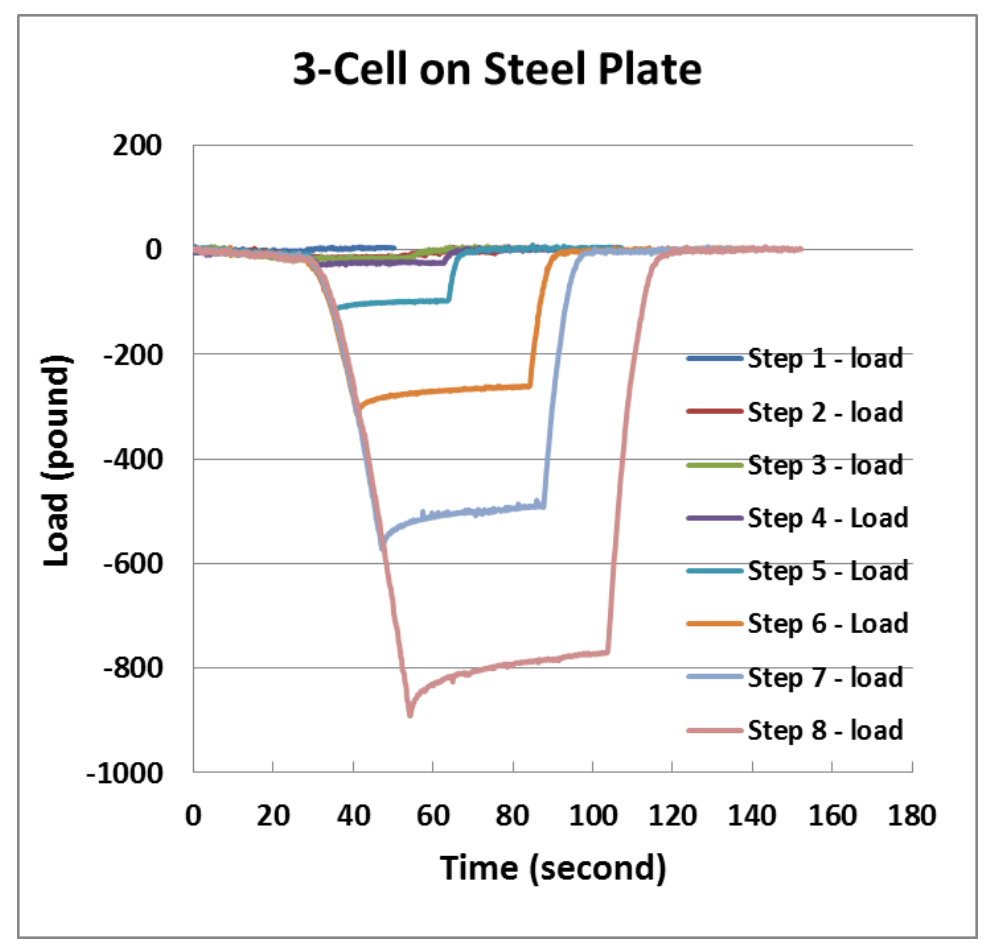

Fig. 9. Load vs. Time curves of the eight indentations for Cell No.2 in a 3-cell stack on a steel plate 


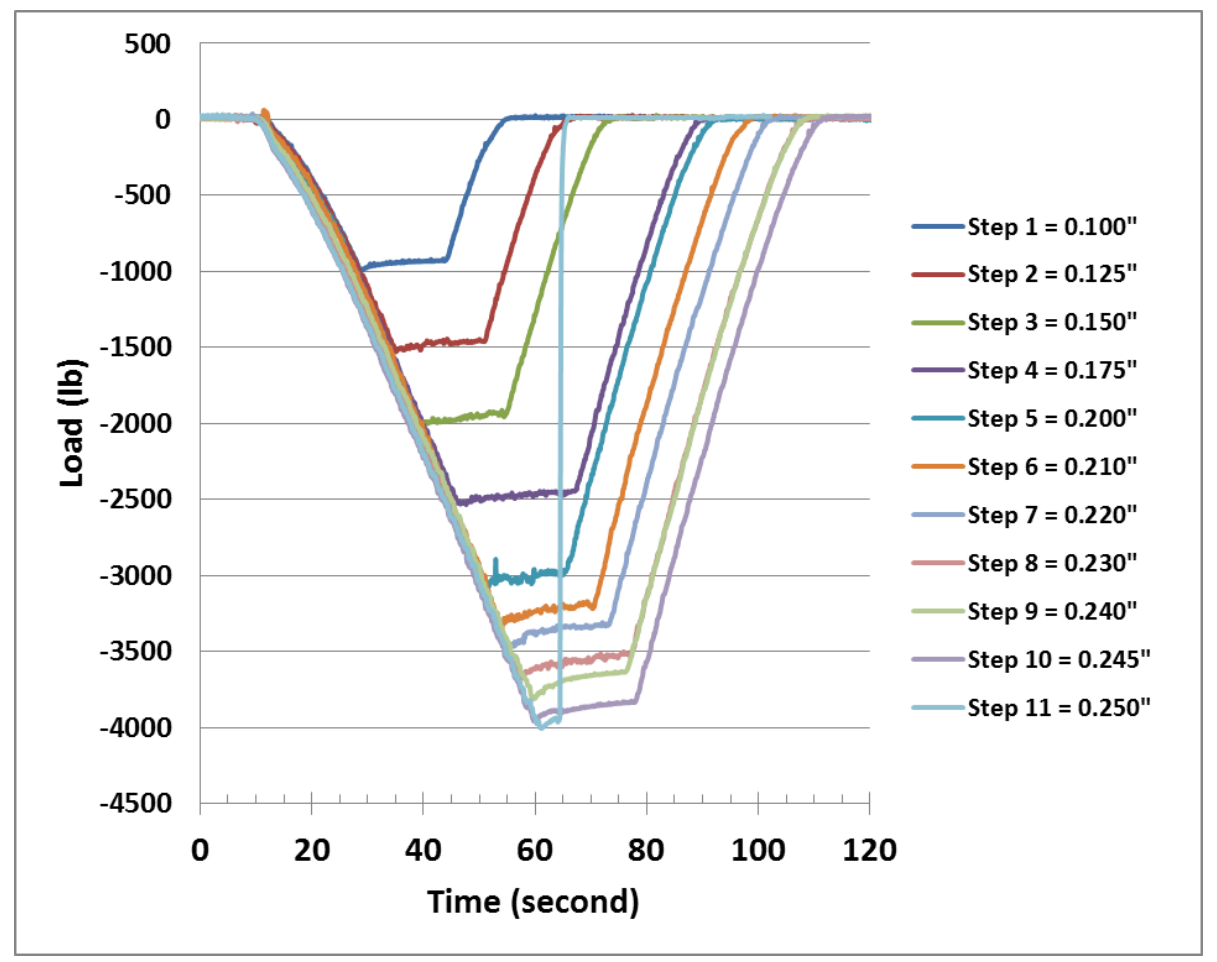

Fig. 10. Load vs. Time curves of the multiple indentations in Cell No. 3-5 against a steel plate

Starting from step No. 5 the load values increased linearly with indentation depth. The final maximum load at 0.200 " depth is about $1 / 3$ of the single cell. However, the initial steps in the 3cell stack showed highly non-linear responses. Figure 10 is the Load vs. Time plot of cells No. 3-5 in an attempt to pin-point the indentation limit for short circuit. The plot shows 11 steps from 0.100 " with 0.025 " increments until 0.200 ", and 0.010 " steps until 0.240 ". The final increment 11 was $0.005 "$ " It was determined that the critical indentation limit for this commercial NMC cell was 0.245 inch ( 0.233 inch of actual displacement). The large tolerance for compression is an overlooked safety feature for Li-ion pouch cells. In order to show the effect of single cell and 3P stack, the maximum load vs. displacement is shown in Fig. 11. For single cell on a steel plate, cell \#1 and \#2 were very repeatable except for the first two points. This was because of the slight differences in the starting point and the loading variations when the indenter and the cell made initial contact.

The cells were opened to analyze their internal state after the indentations. Figure 12 shows optical images of the opened cell stack and separators. The polymer separators were white in color and become transparent when stretched. When placed on a black background, the thinned areas appear dark. The first three steps show little thinning with little increase in darkness with increasing indentation depth. Starting from step \#4 the thinning becomes notable to the naked eye. 


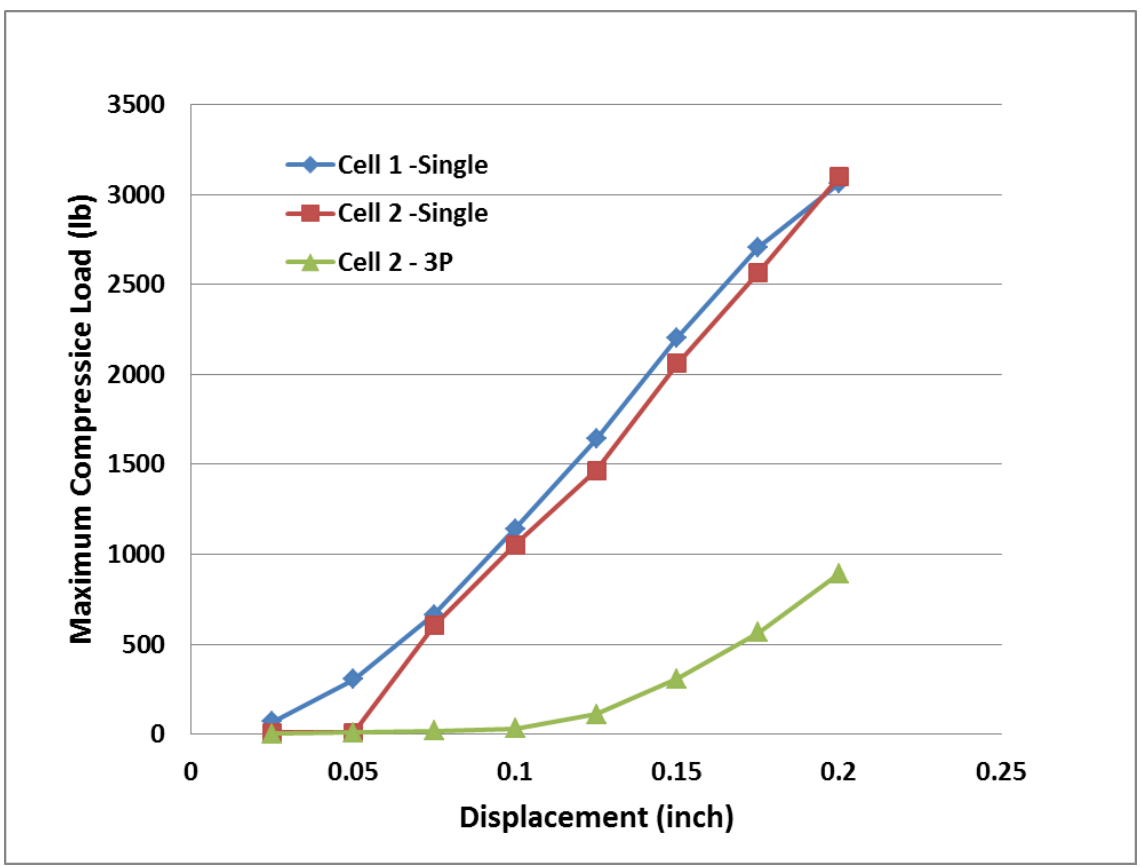

Fig. 11. Maximum compressive load vs. displacement of the indentation tests

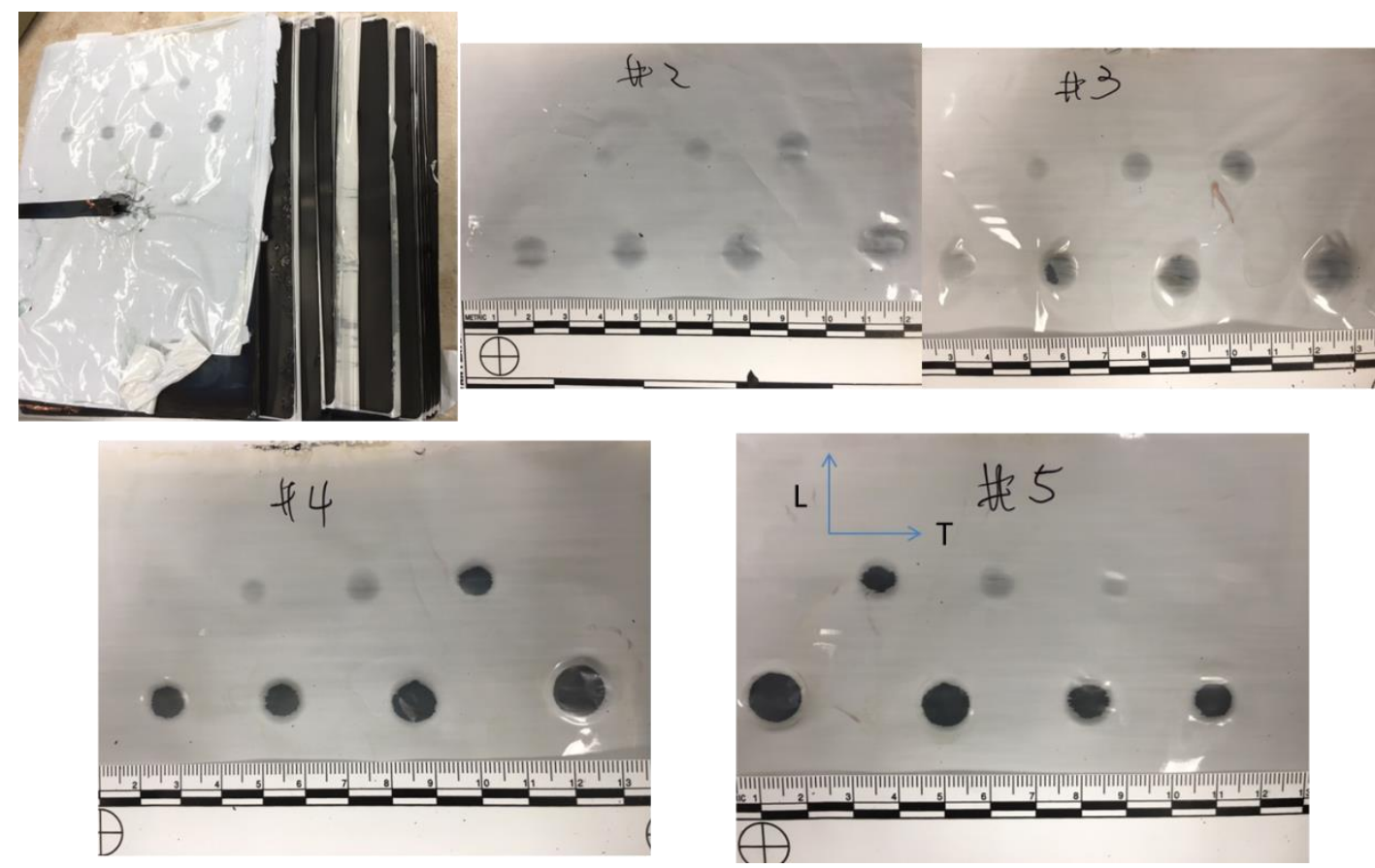

Fig. 12. Images of the opened cell and separators at various depths 


\section{Simulations of cell indentation}

Indentation experiments were simulated using the FEM software package LS Dyna [20]. LS Dyna uses an explicit time integration method and is capable of efficiently modeling nonlinearities in material, structure and geometry. The battery pouch geometry used for the simulation had a length (x-direction) of $80 \mathrm{~mm}$, width (y-direction) of $80 \mathrm{~mm}$ and thickness of $6.54 \mathrm{~mm}$. The displacement for 4 sides along the lateral boundary were constrained in $x-y$ directions i.e. motion along the z-direction was only allowed for those boundary nodes. The indentation test was conducted with a rigid sphere modeled as an analytical surface moving downward at a constant speed. The contact between the rigid sphere and pouch cell was modeled as contact-entity feature with a coefficient of friction of 0.3 . The bottom surface of the cell model was constrained by a rigid wall.

\subsection{Material models}

The architecture of a typical Li-ion cell consists of alternating layers of anodes, cathodes and separators. Anode and cathode were modeled with a crushable foam material model (MAT63 in LS Dyna). The input for this model was elastic modulus, Poisson's ratio, hardening curve in compression and a tensile-cutoff value in tension. Due to high percentage of voids and a low Poisson's ratio in electrode material it can be modeled similar to crushable foam material. MAT63 material model had been used in previous battery deformation studies $[8,17]$. We did not consider component failures, so that a high value for tensile cutoff stress ( $1 \mathrm{GPa}$ ) was used for both positive and negative electrode material. The piecewise linear isotropic plasticity material model (MAT-24) [20] was used for separator layer. The active material constitutes approximately 80 percent volume in the jellyroll, so that we also used MAT-63 material model for homogenized material. Material properties for homogenized layer are calculated by Voigt average technique [21] based on properties of each constituent layer. For negative and positive electrode material the value of $\mathrm{E}$ was 0.515 and $0.467 \mathrm{GPa}$, while for separator material value for $E$ was $0.5 \mathrm{GPa}$. Based on thickness of each component layer, the volume fraction in a cell for negative electrode, positive electrode and separator was $0.41,0.52$ and 0.07 respectively. Poisson's ratio for electrode material and separator was 0.01 and 0.3 . The value of effective Young's modulus for homogenized cell material was determined as $0.495 \mathrm{GPa}$.

\subsection{FE model of single cell and cell stack}

A schematic of the single cell model is shown in Fig. 13. The pouch cell consisted of 17 jellyroll layers along the thickness direction. Each jellyroll layer was composed of one negative electrode, one positive electrode, and two separator layers, as shown in Fig. 13(b). In this study, the components of the top 4 jellyroll layers were fully resolved, i.e., one element along thickness direction for each component. Remaining 13 jellyroll layers of the cell were modeled as a single homogenized material. On the basis of our previous study we had determined that resolving the top four layers is sufficient [22]. 


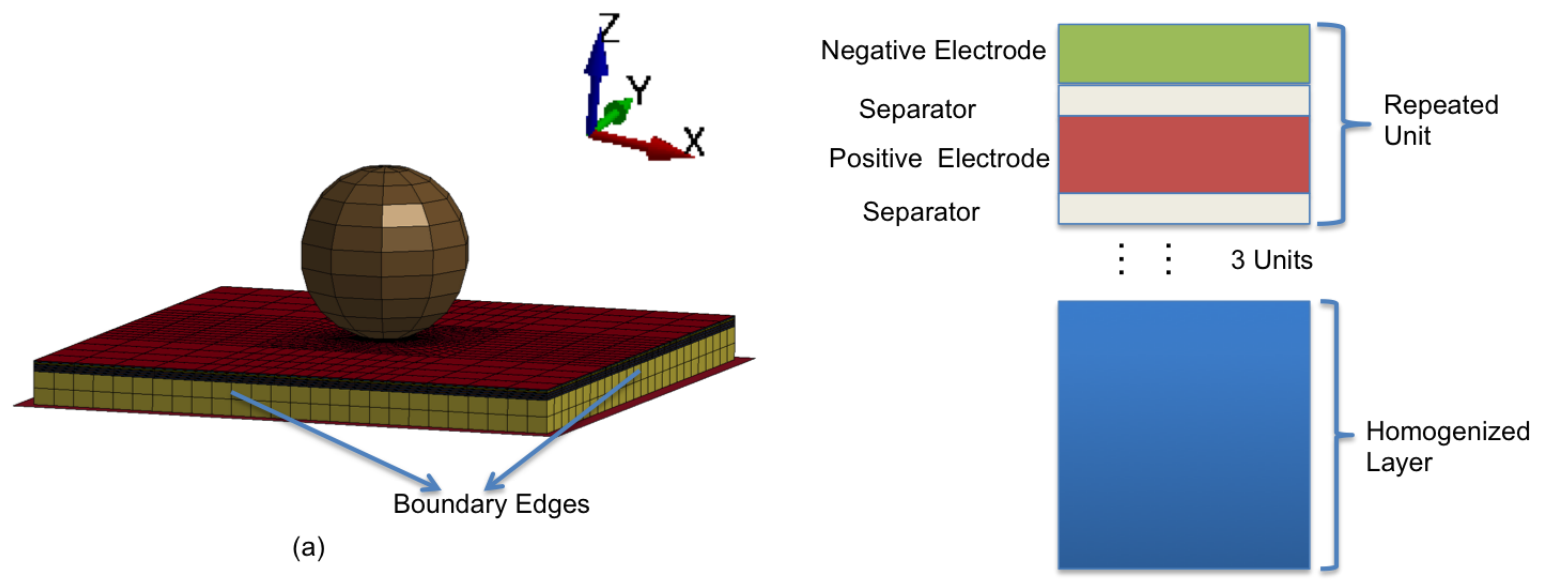

(b)

Fig. 13. Simulation of spherical indentation (a) Mesh of the single cell with a spherical indenter (b) Schematic along the thickness direction of the cell

Fully integrated solid elements were used to mesh the battery cell. The different constituents of the resolved top 4 jellyroll layers were perfectly bonded with each other. Contact at the top surface in the homogenized layer was tied with nodes at the bottom surface of resolved layer using "contact tied surface to surface" keyword.
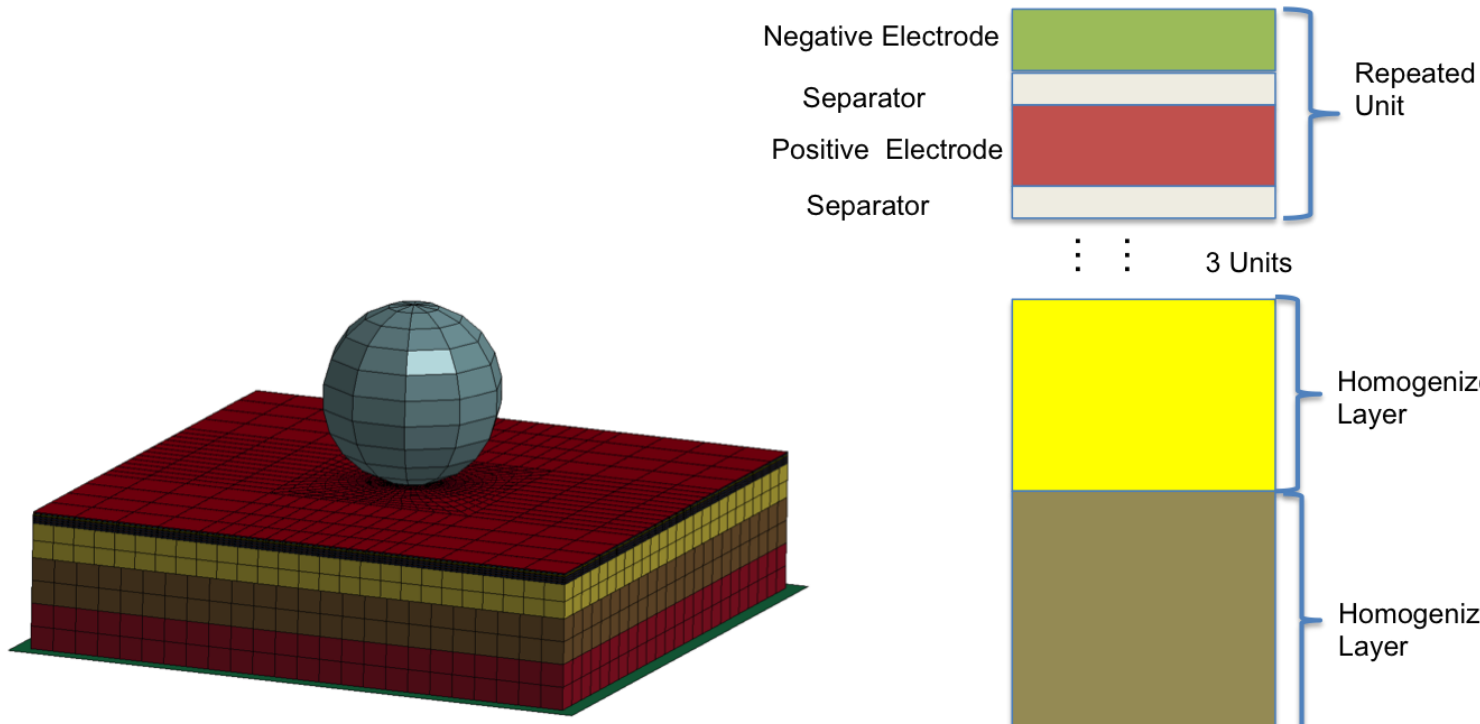

(a)

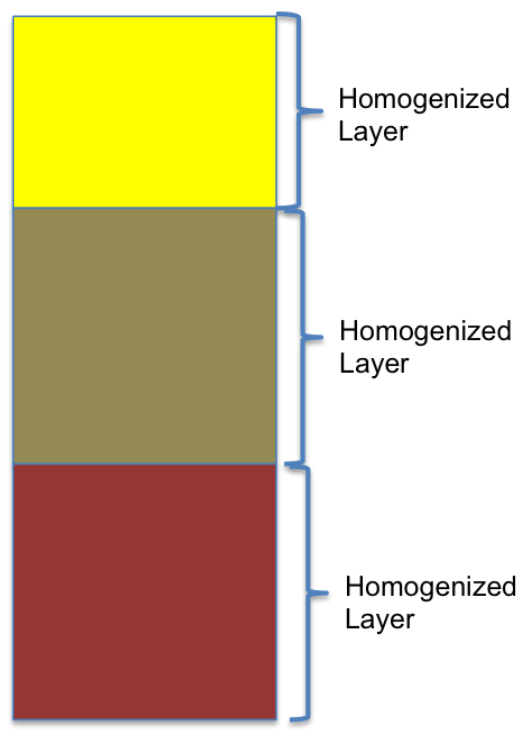

(b)

Fig. 14. Simulation of spherical indentation for 3 cell stack (a) Mesh of the 3 cell stack with a spherical indenter (b) Schematic along the thickness direction of the cell 
Simulation configuration for a stack of 3 cells is shown in Fig. 14. For the top cell, the first four jellyroll layers were fully resolved similar to the single cell case, and the remaining structure was treated as one homogenized material. The bottom 2 cells were modeled as one single material as shown in Fig. 14 (b). Contact interface was used between individual cells.

The load displacement curve comparison between simulations and experiments (Fig. 11) for case of single cell and stack of 3 cells are shown in Fig. 15(a) and 15(b) respectively. There was a relatively good match between the experiments and simulation results for both 1-cell and 3-cell stacks, illustrating the validity of the material models and material parameters presented in the previous section.

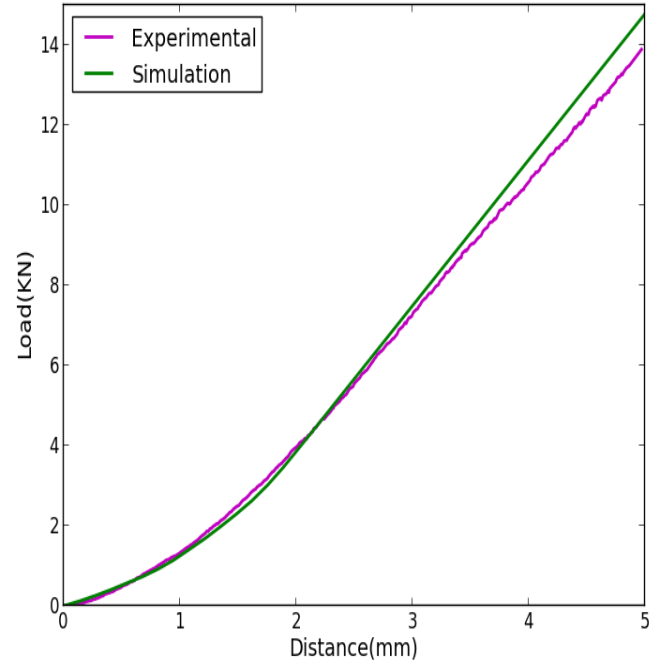

(a)

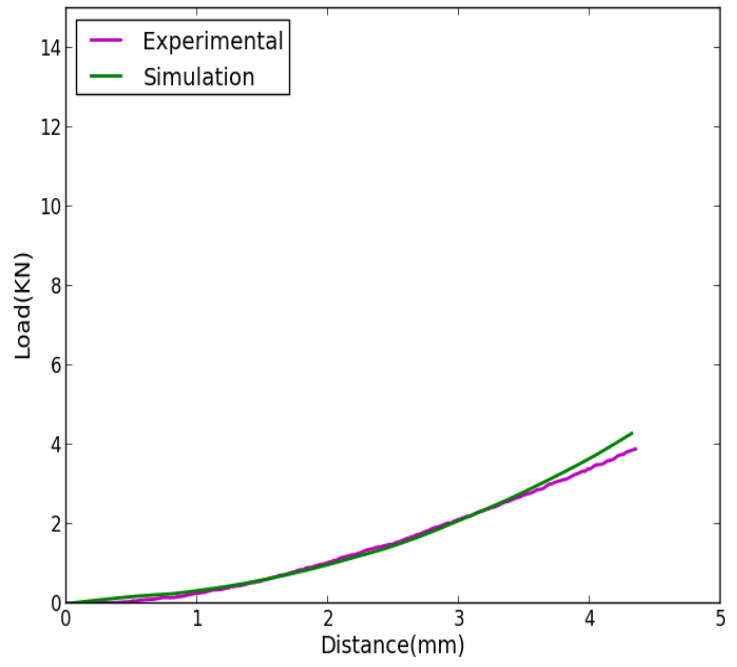

(b)

Fig. 15. Load vs. Displacement curves for (a) single cell indentation; (b) indentation of stack of 3 cells

As discussed in the experiment section, there was a change in the color of the separator as indentation progressed due to its thinning. This change in thickness was represented in the simulation by z-strain (thickness strain). In Fig. 16(a) we compare the deformed region of separator layer at the top of the cell at indenter displacements of 0.1 and 0.2 inch for 1 -cell case. With increased indenter displacement, the area of deformed portion increased. After a critical deformation, the separator fails causing the contact of opposite electrodes, which caused internal short in the pouch cell. The area of the deformed plastic region of the separator obtained from test and simulation is plotted in Fig. 16(b). Area was measured using the ImageJ software [23]. The correlation of area is tested using a linear fit, $R^{2}$ value is 0.9952 , and this measure of $R^{2}$ for linear regression implied a good agreement in measure of area obtained from test and simulation. 

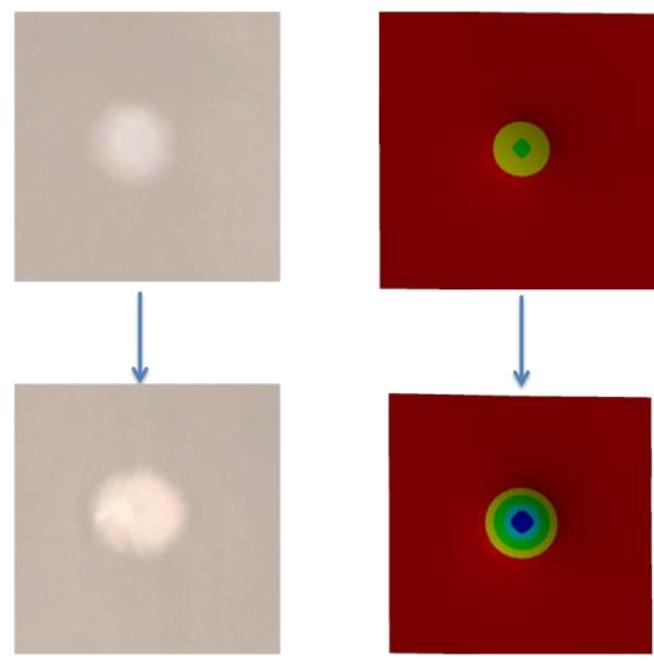

(a)

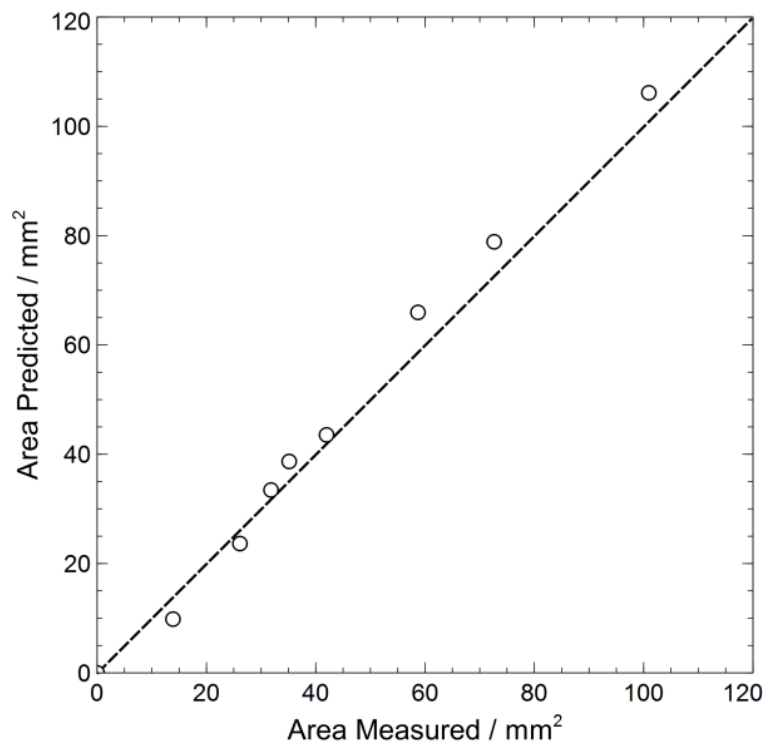

(b)

Fig. 16. (a) Thinning of top separator layer with indenter displacement, top row experimental and simulation images are at indenter displacement of 0.1 inch while the bottom row are at indenter displacement of 0.2 inch; (b) Area of deformed region obtained from test and simulation

\subsection{Effect of anisotropy of separator}

To model the anisotropic behavior of the separator, we used Barlat constitutive model [24] (Mat-36 in LSDYNA). This constitutive model is commonly used to model behavior of sheet metals under plane stress condition [25]. Stress-strain curves obtained from the tensile test of separator were used as input for this material model. The other material constants were elastic modulus equal to $0.5 \mathrm{GPa}$ and Poisson's ratio of 0.3 . We did not get any notable difference in the load-displacement curve using an anisotropic model for separator compared to the isotropic model because the stiffness for separator is same in both the case. 
In the previous section we have simulated the indentation of the cell without any failure criteria for cell components. Failure was introduced in the model by assuming that with increased indentation, separator layer thickness was reduced, and when the thickness was sufficiently reduced, separator failed and caused short circuit in the cell. We modeled this failure behavior by maximum strain (strain in thickness direction) criteria for separator layer elements. In this criterion, an element was deleted when the strain in the element was equal to or greater than a predefined value. We varied the predefined value for strain to get a good match with experimental finding (Fig. 17) and found the strain value to be 0.65 .

As previously discussed, we have considered isotropic and anisotropic material models for the separator. We simulated the failure (short-circuit) of the cell using these 2 models. For the isotropic model we have 2 cases, in the first the mechanical properties in all the directions were same as machine direction, and in the other the properties in all the directions were same as transverse direction value. The value for failure strain was 0.65 in all the cases. Since the separator was stronger in the machine direction (MD) compared to the transverse direction (TD), the failure load was higher for MD as compared to TD case as seen in Fig. 17. The anisotropic model predicted the failure load and displacement value in between these two isotropic models for the same failure strain in the separator. By changing the failure strain for any of these cases (isotropic/anisotropic) load-displacement curve similar to experimental result can be obtained. However, as shown in Fig. 16 the maximum strain at indentation of 0.2 inch is close to 0.6 , hence 0.65 can be the value corresponding to failure under indentation depth of 0.245 inch. In the present study we have guessed the value for failure strain, but in future studies we can perform bidirectional tension test on the separator to obtain the value at which the separator will fail and use that value for the simulation.

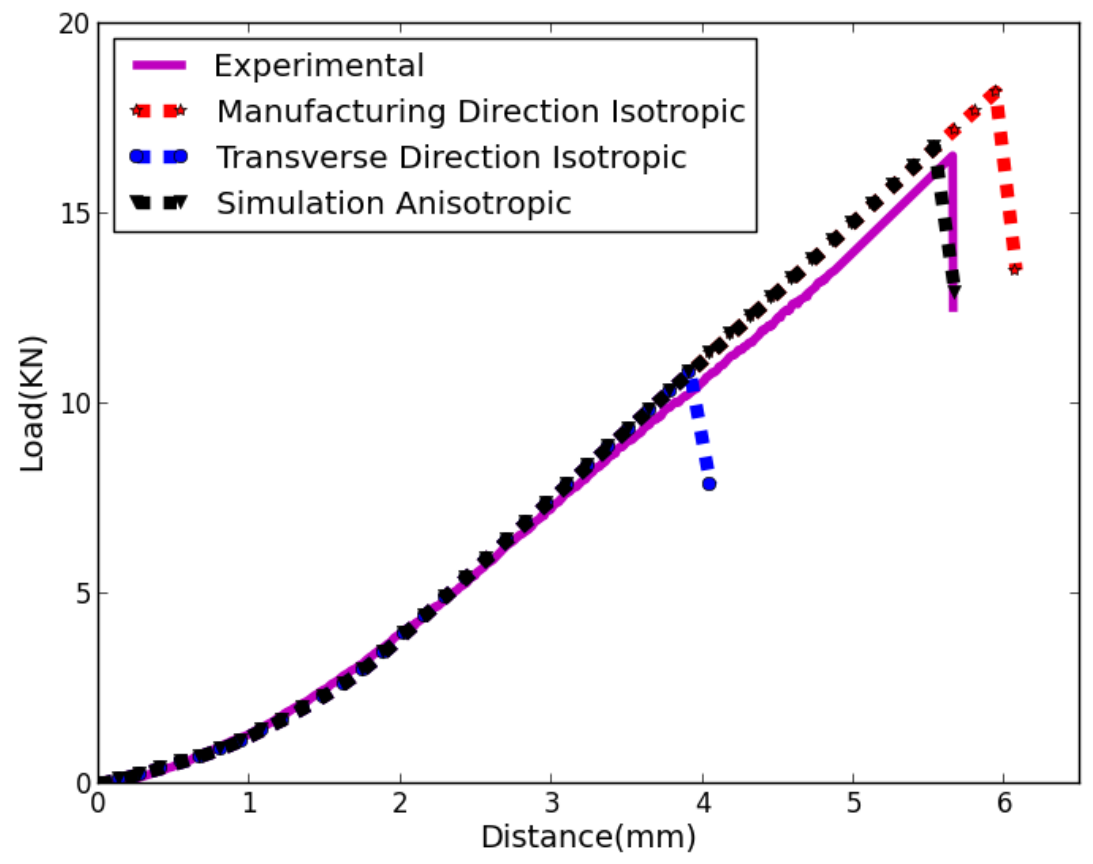

Fig. 17. Load-displacement curve with failure criteria for separator layer 


\subsection{Layer-resolved versus homogenized model}

In this section we have compared the layer resolved model to the homogenized model by performing simulations for different sizes of spherical indenter. We found that calibration of a failure criterion for the cell in the homogenized model depends on the indenter size, whereas in the layer-resolved model, such dependency is greatly diminished.

Most of the studies to date use homogenization approaches $[17,26]$ to represent Li-ion cell without resolving the cell layered structure. Crushable foam material model is typically used to represent the cell as one single material in homogenized model. In this approach the failure criterion is determined by prescribing a threshold value of internal variables in the constitutive model to match the experimental result. This calibration is dependent on physical and mechanical attributes of the cell (experiments have to be repeated for each new cell), the size of the indenter, and on the model discretization. Only recently, there have been attempts to include a representation of various layers that make up the cell $[27,28]$. In this modeling approach there was an explicit representation of each individual component, but all individual layers of each component were consolidated into one thick layer, for example, 40 separator layers in the cell were modeled as one component. Even though this approach considered the properties of different components in the cell, and general sequence of the materials, it still required different critical tensile strain values for different indenter sizes to match the experimental data [27].

A schematic of the layer-resolved model for a single pouch cell with spherical indenter is shown in Fig. 18 (a), and the corresponding homogenized model is shown in Fig. 18(c). The approach for layered resolved model was described in the previous section. In the homogenized material-modeling approach, the jellyroll was assumed to be composed of a single isotropic material and used a crushable foam (MAT-63) model in LS-DYNA to describe the constitutive behavior. In this model, similar to the approach for reinforced concrete, a tensile cut-off stress was used to predict load and displacement at the point of failure. The value of this parameter can be obtained by adjusting it to match the experimentally observed maximum load at failure of Li-ion cell under indentation by a rigid sphere [26]. This method required a set of calibration experiments to be performed when new electrode materials or different cell parameters were introduced and thus was limited in its predictive capability. By performing a numerical study we demonstrated that the value of tensile cut-off stress was also dependent on size of spherical indenter used. To be consistent, we used the same mesh resolution in all 3 directions for both homogenized (Fig. 18(c)) and layer-resolved models (Fig. 18(a)). Material parameters for homogenized model were taken from [29].

We used spherical indenters of three different diameters (12.5, 28.6 and $44.5 \mathrm{~mm})$ for the simulation study. In the case of layer-resolved model, we used the $12.5 \mathrm{~mm}$ indenter to calibrate the failure strain value $(0.55)$ in the separator, and used that failure parameter to predict the deformation in the cells when $28.6 \mathrm{~mm}$ and $44.5 \mathrm{~mm}$ indenters were used. As shown in Fig 19(a), the simulation results closely match the experimental results [26] for all three indenter sizes. The value for load was higher in the case of $44.5 \mathrm{~mm}$ indenter compared to experimental result due to extra stiffening in the material at higher value of compression, but the displacement of indenter at the moment of the short circuit was predicted correctly.

We repeated the spherical indentation simulation using a homogenized material model $\left(E=0.5 \mathrm{GPa}, v=0.01\right.$, tensile cut-off stress $\left.Y_{t}=35.4 \mathrm{MPa}\right)$ for $12.5 \mathrm{~mm}$ punch diameter. Material properties were adjusted such that the simulation result was the same as the experimental value for $12.5 \mathrm{~mm}$ diameter punch, as shown in Fig. 19(b). Using the same material parameters for homogenized model we performed the simulation for 2 different punch diameters of $28.6 \mathrm{~mm}$ and $44.5 \mathrm{~mm}$. As shown in Fig 19(b), the simulation results were not the same as experimental results for these two cases. To get the similar force-strain curves using homogenized material 
model, we had to adjust the failure parameter $\left(Y_{t}\right)$ for each indenter size, as shown in Fig 19(c). The values of $Y_{t}$ used in these three cases were 35.4, 42.7 and $48.2 \mathrm{MPa}$ respectively.

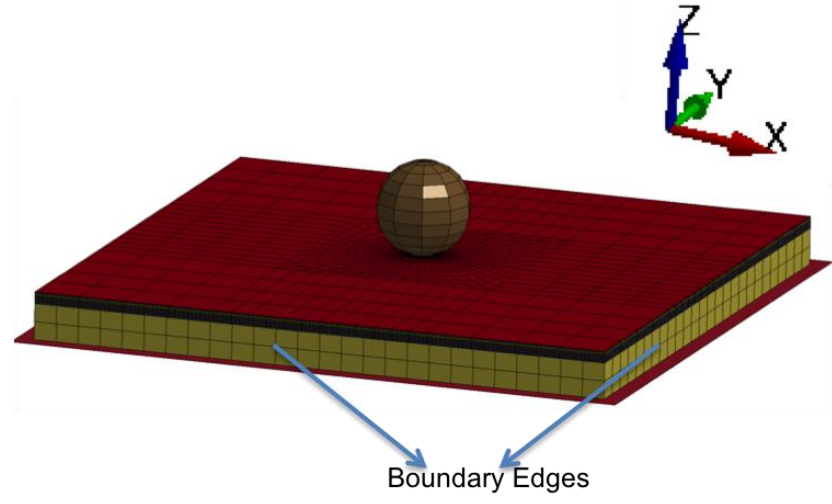

(a)

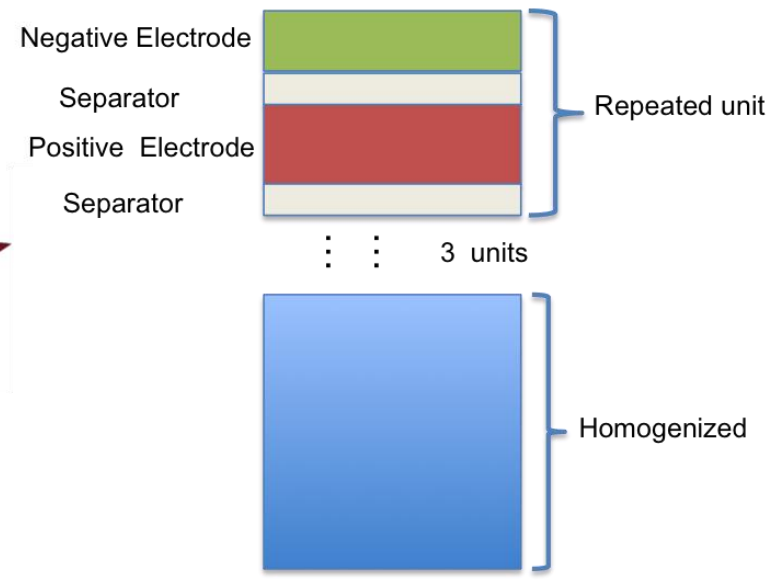

(b)

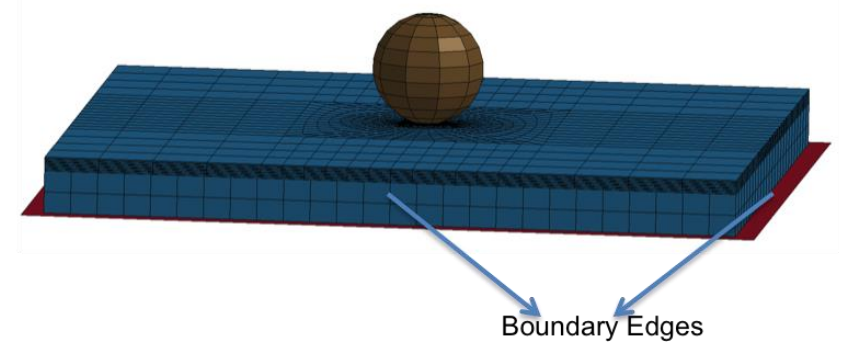

(c)

Fig.18. (a) Non-uniform mesh of layer-resolved model (b) Cross-section view of an individual cell, where each layer is represented by different material (c) Mesh of homogenized model 


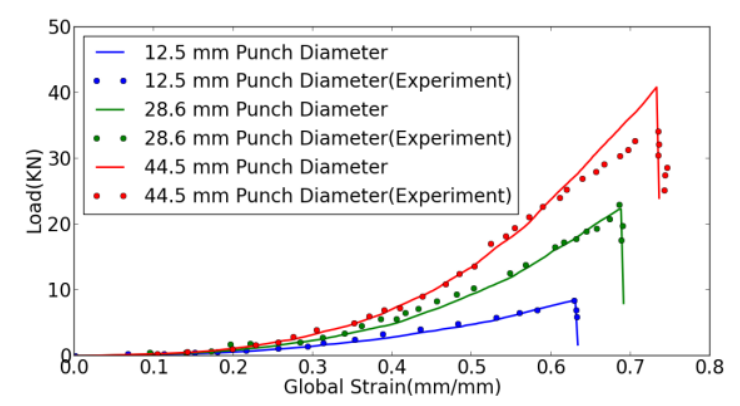

(a)

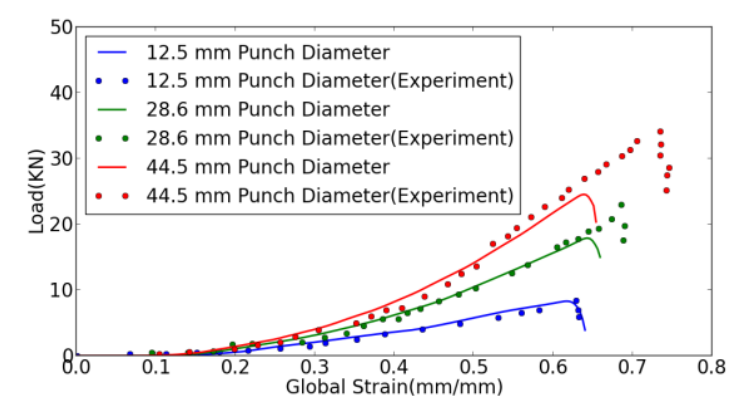

(b)

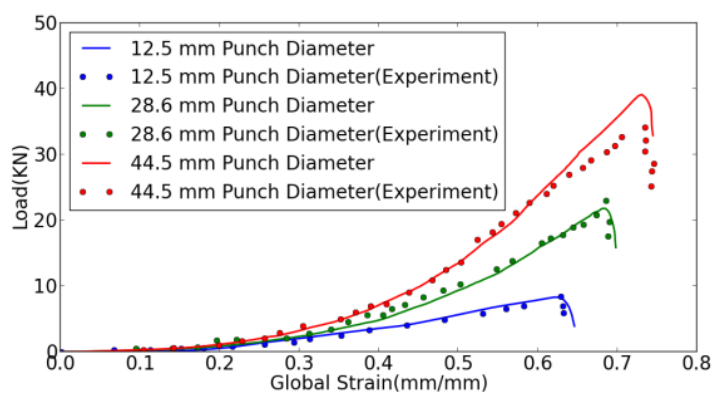

(c)

Fig. 19. Force-Strain responses for three different indentation tests, with failure parameter calibrated with $12.6 \mathrm{~mm}$ diameter punch, for (a) Layer-resolved Model (b) Homogenized Model (c) different failure parameter is used for each punch size in case of homogenized model

\section{Coupled electrochemical-electrical-thermal simulations}

In this section we describe the two new capabilities that have been demonstrated as part of this project. The first task is to construct a hierarchy of cell components to form a pouch cell and battery module and conduct a coupled EET simulation using high performance computing (HPC) framework. The second task is to perform a consistent internal short multi-physics simulation at the electrode layers.

\subsection{Battery module simulations}

In a large-scale battery pack simulation, the reduced order equivalent circuit models have been shown to be inaccurate in predicting the response when inhomogeneity of properties are involved. To account for cell-to-cell variations in a battery module, it is important to set up a highly resolved physics based simulation. A highly resolved simulation entails decomposing the domain and modeling each constituent material component with relevant physics. We set up this large-scale battery module simulation by exploiting the construction of large format Li-ion cells and decomposing the physical problem into several sub-domains. These sub-domains, such as electrodes, current collectors and separators, are stacked against each other and are constrained using nonlinear boundary conditions. The parameters used for the 3D electrochemistry model are given in [30]. Using these properties we have carried out a validation study 
at $1 \mathrm{C}$ and $3 \mathrm{C}$ constant current discharge. The comparison of the potential discharge curves can be seen in the Fig. 20.

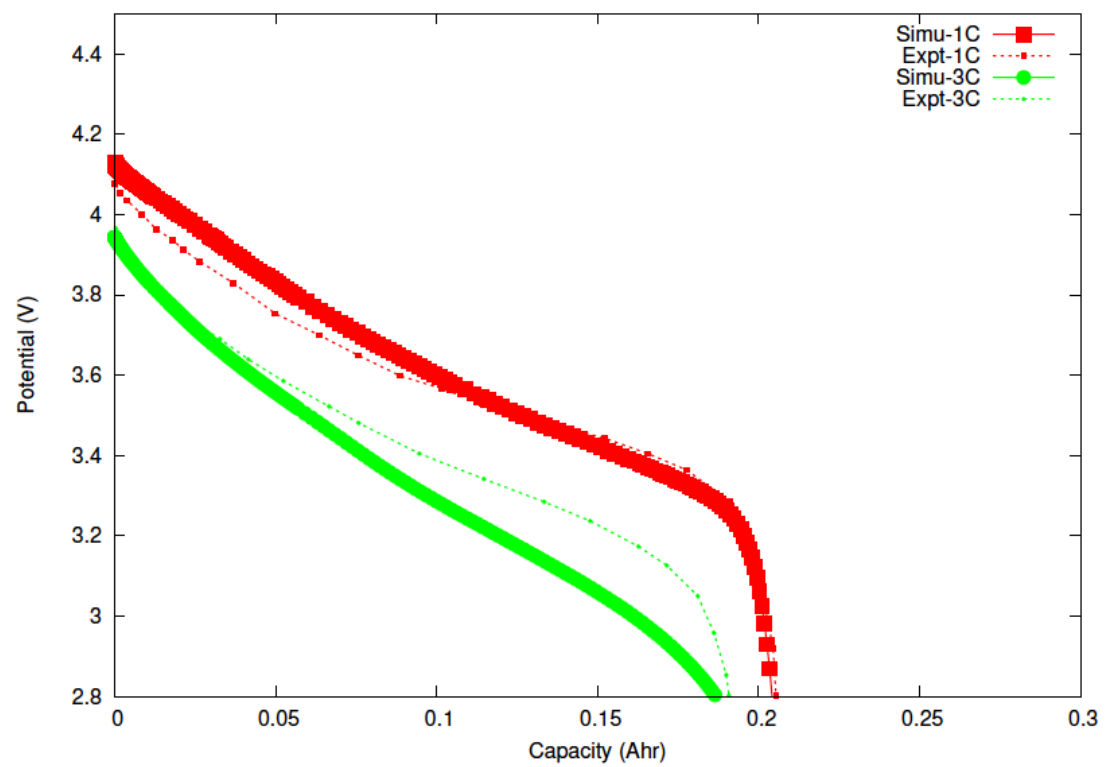

Fig. 20. Comparison of discharge curves for $\mathrm{NMC}(333)$ at $1 \mathrm{C}$ and $3 \mathrm{C}$ with experiment.

With the validated electro-chemical model we have coupled thermal transport model to evaluate the thermal distribution across the module. For the thermal boundary we have used adiabatic conditions on the non-contact surfaces and a perfect contact on the stacked surfaces of the internal domains. Under constant current discharge conditions we observe in Fig. 21 below that the internal core of the module is heated and heat is transported to the aluminum case as it acts as a heat sink. Multiple modules can be stacked together as a battery pack consisting of 1350 independent domains with 16 million degrees of freedom and the simulation takes a wall clock time of 24 hours on 1024 cores.
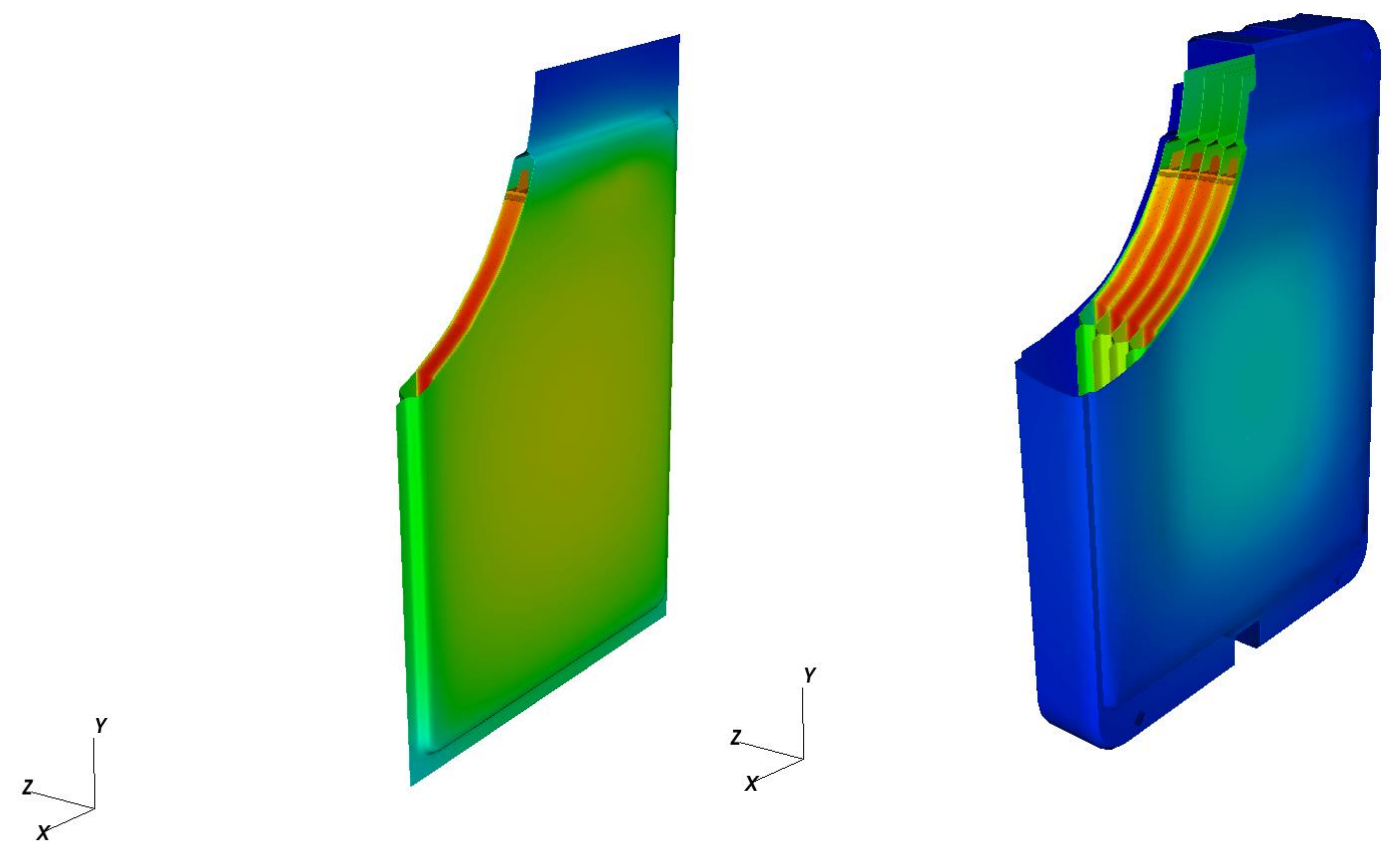

Fig. 21. Temperature distribution across single pouch cell and four cell module 


\subsection{Internal short of single electrode layer}

During the internal short of the battery under mechanical deformation the shorting propagates across the electrode layers. The shorted layer acts as a closed circuit for the rest of the electrode layers and cells connected through tabs. Due to low impedance at the shorted region, the current distribution across the electrode layers and the rest of the connected cell is non-uniform. To understand the spatial and transient characteristics that initiate the thermal runaway processes it is necessary to solve the 3D electro-chemistry and thermal transport using a coupled technique. We capture the internal short condition by introducing a low resistance in the contact region predicted by the mechanical simulations.

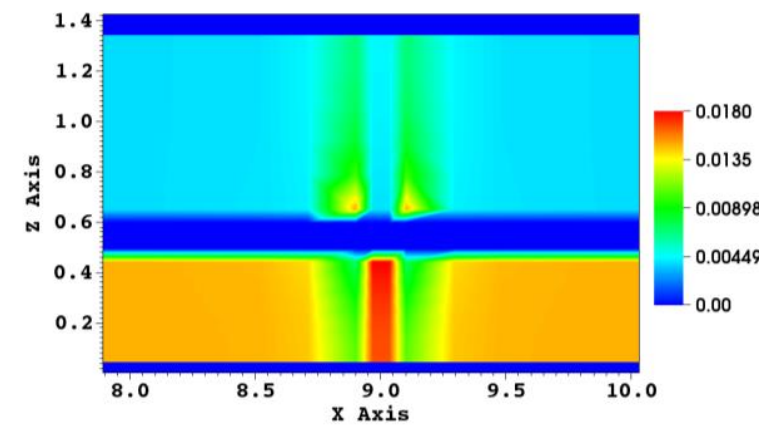

(a)

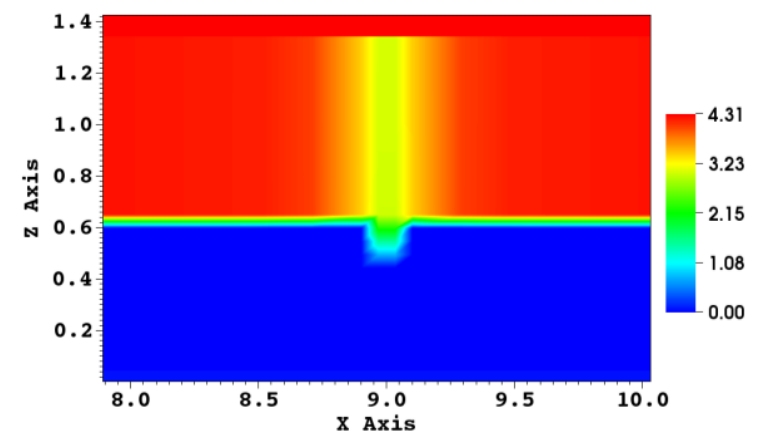

(c)

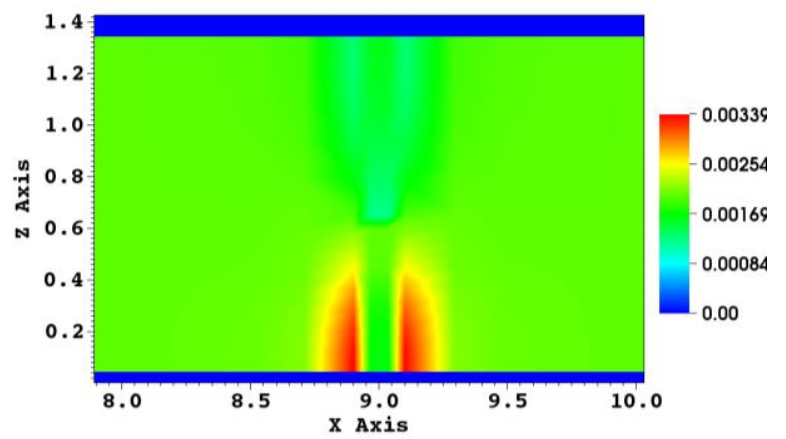

(b)

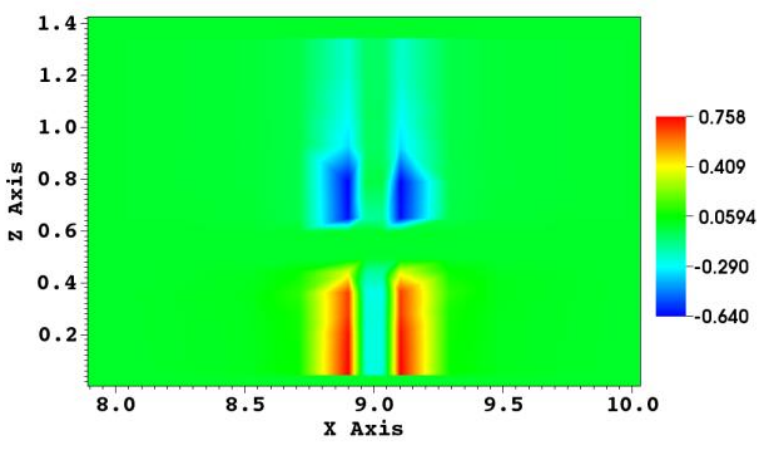

(d)

Fig. 22. Exploded views of the electrode/electrolyte concentrations, solid phase potential and exchange current density at the end of $20 \mathrm{sec}$.

As the short is introduced between the electrodes using low contact resistance value, we see the solid phase potential instantly drop across the cell sandwich thickness as shown in Fig. 22(c). At the initialization stage this short element introduced equilibrates the potential drop across the anode/cathode electrodes. This initialization process is described in reference [31] that computes the consistent solution for the given boundary conditions. Due to this potential drop around the short, high exchange current density gradients are generated, and as we step in time through the solution state, these gradients eventual decay to zero value. In this process the intercalation reaction and transport of lithium from electrolyte to electrode takes place, and lithium concentration depletes and accumulates around the short region as shown in Fig. 22(a) and 22(b). As these intercalation reactions take place, heat is generated across the shorted region and subsequent thermal transport takes place across the current collectors, as shown in Figs. 23, 24. 


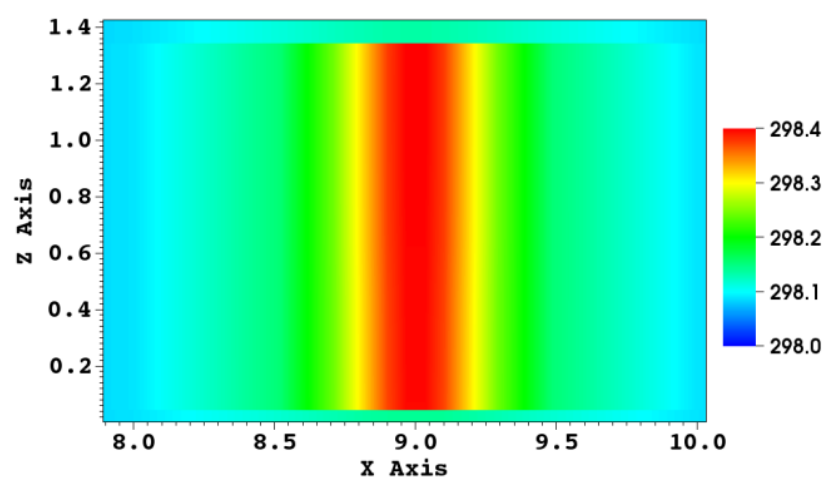

Fig. 23. Exploded view of temperature at the end of $20 \mathrm{~s}$. of internal short circuit

With this study we were able to consistently impose an internal short across the electrode layers and compute a coupled multi-physics solution. In the future work we will electrically couple the shorted layers with the rest of the layers in a cell and module.

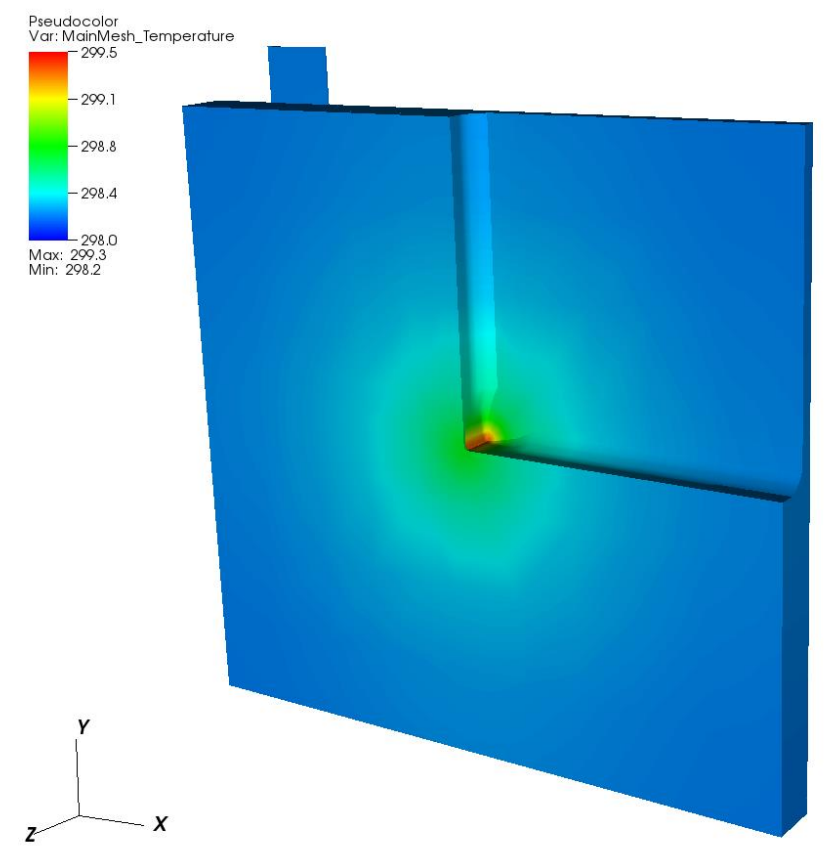

Fig. 24. Temperature distribution during internal short across the electrode layers. 


\section{Conclusions}

Progressive indentation tests have been carried to systematically study the mechanical deformation of Li-ion cells. Indentation tests were performed on a single cell and 3-cell stacks. The indentation depth limit for the 1" diameter sphere is about 0.233 " which corresponds to $90 \%$ of the cell thickness. Load-displacement curve obtained from the test was compared to those obtained by simulation. By detailed analysis we found thinning of the separator, which might be one of the potential reasons for short due to mechanical indentation. Using an anisotropic material model for the separator, better match between the experimental results and prediction was found.

We demonstrated the capability to formulate and solve an internal short circuit problem in a consistent manner. The results are demonstrated on one cell sandwich and reveal the capability to predict concentration and potential gradients in the vicinity of the short circuit. We also performed a coupled simulation of Li-ion battery module involving electrochemistry, thermal and charge transport. Further efforts will be directed in formulation of short circuit criterion due to mechanical abuse of battery module and performing corresponding EET simulations. 


\section{References}

[1] J.B. Goodenough and Y. Kim, Chemistry of Materials, 22-3, 2010, 587-603.

[2] L. Hollmotz, M. Hackmann, in: 22nd International Technical Conference on Enhanced Safety of Vehicles (ESV), (2011) 11-0269.

[3] National Highway Traffic Safety Administration (2006). "Electric Powered Vehicles: Electrolyte Spillage and Electrical Shock Protection", FMVSS No. 305. U.S. DOT.

[4] Kai, X., Xueping, W., et al. (2014). "Comparative research on standards and regulations of electric vehicle post crash safety requirement Transportation Electrification Asia-Pacific" (ITEC Asia-Pacific), 2014 IEEE Conference and Expo.

[5] SAE International (2014). "Recommended Practice for Electric, Fuel Cell and Hybrid Electric Vehicle Crash Integrity Testing" SAE J1766.

[6] SAE J2464-200911 (2009). "Electric and Hybrid Electric Vehicle Rechargeable Energy Storage System (RESS) Safety and Abuse Testing." SAE International, Revision $11 / 06 / 2009$.

[7] SAND 2005-3123 Technical Report (2005). "Freedom CAR Electrical Energy Storage System Abuse Test Manual for Electric and Hybrid Electric Vehicle Applications." By Doughty, D., and Crafts, C., Sandia National Laboratories http://prod.sandia.gov/techlib/access-control.cgi/2005/053123.pdf

[8] E. Sahraei, J. Meier and T. Wierzbicki, Journal of Power Sources, 220, (2012) 360-372.

[9] UL, in: UL 1642 Standard for Safety for Lithium Batteries, UL, 1999

[10] Battery Association of Japan, Presentation at UN Informal Working Group Meeting, November 11-13, 2008, Washington, DC

[11] M. Keyser, D.Long, Y.S. Jung,A. Pesaran, E. Darcy, B. McCarthy, L. Partrick and C. Kruger, in: Advanced Automotive Battery Conference (AABC), January 25-28, 2011, Panadena, CA

[12] R. Takata, C. McCoy, D. Ofer, R. Stringfellow, B. Barnett and S. Sriramulu, Proceedings of 44th Power Sources Conference, Curran Associates, Inc. Red Hook NY, (2010) p12

[13] J.P. Peres, F. Perton, C. Audry, P. Biensan, A. de Guibert, G. Blanc, M. Broussely, Journal of Power Sources, 97-8 (2001) 702-710

[14] L. Florence, in: Battery Power, Dallas, Texas, 2010, p. 576

[15] W. Cai, H. Wang, H. Maleki, J. Howard, E. Lara-Curzio, Journal of Power Sources, 196 (2011) $7779-7783$

[16] F. Ren, T. Cox, H. Wang, Journal of Power Sources, 249 (2014) 156-162

[17] E. Sahraei, R. Hill, T. Wierzbicki, Journal of Power Sources, 201 (2012) 307-321

[18] T. Wierzbicki, E. Sahraei, Journal of Power Sources, 241 (2013) 467-476

[19] R. Spotnitz, R. Muller, The Electrochemical Society Interface, 12 (2012) 57-60

[20] "LS-DYNA Keyword User's Manual Volume II Material Models" Version 04/06/16 (r:7556), Livermore Software Technology Company, Livermore, CA, April 2016

[21] Voigt W. 1928. Lehrbuch der Kristallphysik. Teubner

[22] Crash Model for Advanced Automotive Batteries NHTSA Phase 1 Report 
[23] ImageJ http://rsb.info.nih.gov/ii/docs/

[24] Barlat, F., Lian, J.: Plastic behavior and stretchability of sheet metals. Part I: a yield function for orthotropic sheets under plane stress conditions. Int. J. Plast. 5, (1989) 51-66.

[25] D.Banabica,, H.Aretzb, D.S.Comsaa, L.Paraianua: An improved analytical description of orthotropy in metallic sheets Int. J. Plast. Volume 21, Issue 3, March 2005, Pages 493512)

[26] E. Sahraei, J. Meier, T. Wierzbicki, J Power Sources 220 (2012), 360-372.

[27] Chao Zhang, Shriram Santhanagopalan,, Michael A. Sprague, Ahmad A. Pesaran Journal of Power Sources 298 (2015) 309-321

[28] Chao Zhang, Shriram Santhanagopalan, Michael A. Sprague , Ahmad A. Pesaran Journal of Power Sources 290 (2015) 102-113

[29] E. Sahraei, J. Campbell, T. Wierzbicki J. Power Sources (2012) 360-372

[30] Chandrasekaran, R., Quantification of contributions to the cell overpotential during galvanostatic discharge of a lithium-ion cell, J Power Sources, 262 (2014), 501-513.

[31] S. Allu, S. Kalnaus, S. Simunovic, J. Nanda, J.A. Turner, S. Pannala, A three-dimensional meso-macroscopic model for Li-ion intercalation batteries, J Power Sources 325 (2016), 42-50. 


\section{Appendix}

Table 1. Cell dimensions and nominal capacity

\begin{tabular}{ccccccc}
\hline Manufacturer & $\begin{array}{c}\text { Cell width, } \\
\mathrm{mm}\end{array}$ & $\begin{array}{c}\text { Cell height, } \\
\mathrm{mm}\end{array}$ & $\begin{array}{c}\text { Tab height, } \\
\mathrm{mm}\end{array}$ & $\begin{array}{c}\text { Cell thickness, } \\
\mathrm{mm}\end{array}$ & $\begin{array}{c}\text { Nominal } \\
\text { Capacity, } A h\end{array}$ & $\begin{array}{c}\text { Nominal } \\
\text { Voltage, } V\end{array}$ \\
\hline $\begin{array}{c}\text { Farasis } \\
\text { Energy, Inc }\end{array}$ & 161 & 230 & 10 & 6 & 25 & 3.65 \\
\hline
\end{tabular}

Table 2. Calibration of indenter displacement

\begin{tabular}{cc}
\hline \hline Target Displacement (inch) & Actual Displacement (inch) \\
\hline 0.100 & 0.096 \\
0.125 & 0.120 \\
0.150 & 0.144 \\
0.175 & 0.168 \\
0.200 & 0.190 \\
0.210 & 0.200 \\
0.220 & 0.209 \\
0.230 & 0.219 \\
0.240 & 0.228 \\
0.245 & 0.233 \\
0.250 & 0.236 \\
\hline
\end{tabular}

Table 3. Area of separator that experienced plastic strain under spherical indentation

\begin{tabular}{ccc}
\hline \hline Indenter Depth $(\mathrm{mm})$ & Area measured $\left(\mathrm{mm}^{2}\right)$ & Area predicted $\left(\mathrm{mm}^{2}\right)$ \\
\hline 0 & 0 & 0 \\
0.635 & 13.88 & 9.83 \\
1.27 & 26.13 & 23.65 \\
1.905 & 31.82 & 33.45 \\
2.54 & 35.14 & 38.68 \\
3.175 & 41.98 & 43.54 \\
3.81 & 58.71 & 65.95 \\
4.445 & 72.65 & 78.87 \\
5.08 & 100.95 & 106.13 \\
\hline
\end{tabular}


Table 4. Material constants for Barlat's 3-parameter plasticity model (MAT-36)

\begin{tabular}{lll}
\hline \multicolumn{1}{c}{ Variable } & \multicolumn{1}{c}{ Description } & \multicolumn{1}{c}{ Value } \\
\hline RO & Mass Density & $1.00 \mathrm{e}-6 \mathrm{Kg} / \mathrm{mm}^{3}$ \\
$\mathrm{E}$ & Elastic Modulus & $0.5 \mathrm{GPa}$ \\
$\mathrm{PR}$ & Poisson's Ratio & 0.3 \\
$\mathrm{HR}$ & Load curve in three directions & 7 \\
$\mathrm{P} 1$ & Load curve in 45 degree direction & Average of MD and TD \\
& & direction values \\
$\mathrm{P} 2$ & Load curve in 90 degree direction & TD direction Stress Strain \\
& & curve \\
$\mathrm{m}$ & Exponent in Barlat's Yield Surface & 2.0 \\
r00 & Lankford parameter in 0 degree direction & 1.0 \\
r45 & Lankford parameter in 45 degree direction & 1.0 \\
r90 & Lankford parameter in 90 degree direction & 1.0 \\
Icid & Load curve in 0 degree direction (MD) & TD direction Stress Strain \\
& & curve \\
aopt & Material Axis option is Global Orthotropic & 2 \\
\hline
\end{tabular}

Table 5. Material constants for isotropic crushable foam model (MAT-63)

\begin{tabular}{|c|c|c|c|}
\hline Variable & Description & Value (Anode) & Value (Cathode) \\
\hline R0 & Mass Density & $1.00 \mathrm{e}-6 \mathrm{Kg} / \mathrm{mm}^{3}$ & $1.00 \mathrm{e}-6 \mathrm{Kg} / \mathrm{mm}^{3}$ \\
\hline $\mathrm{E}$ & Elastic Modulus & $0.515 \mathrm{Gpa}$ & $0.467 \mathrm{GPa}$ \\
\hline PR & Poisson's Ratio & 0.01 & 0.01 \\
\hline LCID & Load Curve ID defining stress versus strain & $\begin{array}{l}\text { Stress Stain } \\
\text { curve from } \\
\text { experiment }\end{array}$ & $\begin{array}{l}\text { Stress Stain } \\
\text { curve from } \\
\text { experiment }\end{array}$ \\
\hline TSC & Tensile Cutoff & $1.0 \mathrm{GPa}$ & $1.0 \mathrm{Gpa}$ \\
\hline DAMP & Rate Sensitivity via damping coefficient & 0.05 & 0.05 \\
\hline
\end{tabular}

